\title{
The Regressive Demands of Demand-Driven Development
}

\author{
Sarah Baird, Craig McIntosh, and Berk Özler ${ }^{a}$
}

July 11, 2013

Despite their explicit focus on reaching the poor, many community driven development (CDD) initiatives are only partially successful in targeting spending towards them. This paper examines Tanzania's flagship CDD program and provides new evidence on the mechanisms by which the demand-driven components of the program may undermine the goal of pro-poor funding allocations. We exploit two data sources for the analysis: a census of wards for mainland Tanzania and a census of households in 100 program villages. These data paint a consistent picture at both levels: wealth, education, access to media, and political engagement are positively correlated with the likelihood to apply for the program at the national level, and to be aware of it at the local level. Centrally dictated features of the program - namely predetermined funding allocations to districts and eligibility rules - combine with the decentralized selection process within districts to counteract this initially regressive application pattern and produce a program that is, like many other CDD programs, only mildly pro-poor. Our results suggest that sensitization and outreach prior to the application process will be a critical dimension in making CDD programs more progressive.

Keywords: Targeting; Community Driven Development; Poverty; Elite Capture JEL Classification Codes: H42, I38

\footnotetext{
We thank seminar participants at UC Berkeley and WGAPE. We are also grateful to Michael Futch and Leah Nelson for excellent research assistance. The findings, interpretations, and conclusions expressed in this paper are entirely those of the authors. They do not necessarily represent the views of the International Bank for Reconstruction and Development/World Bank and its affiliated organizations, or those of the Executive Directors of the World Bank or the governments they represent. Baird: sbaird@email.gwu.edu, Özler: bozler@worldbank.org. Corresponding author: McIntosh: ctmcintosh@ucsd.edu. Phone: 858822 1125. Address: 9500 Gilman Drive, La Jolla CA, 92093-0519.
} 


\section{Introduction}

Over the past two decades, community driven or community based development (CDD/CBD) has become an increasingly common way to distribute public assistance, and, in addition to providing much needed infrastructure, is intended to provide a variety of other benefits to communities including poverty reduction, improved social capital, and capacity building at the local government level. Mansuri and Rao (2012) argue that the current wave of interest in localized participatory development started as a reaction to "top-down" development aid that was "... deeply disconnected from the needs of the poor, the marginalized, and the excluded.” (p. 2) CDD programs are supposed to improve on previous approaches by better targeting the available funds to needy communities and also allow those communities to determine their specific needs - hence community- or demand-driven development.

Despite the fact that the poor are explicitly the target group for most of these programs, the empirical literature on targeting performance shows that they tend to be only moderately propoor. ${ }^{1}$ For example, World Bank (2002) found that “...social funds projects have delivered slightly more than proportional benefits to the poor and the poorest.” (p. xi) Beneficiary communities and households are determined by which ones apply and, having applied, get approved. The literature before us has examined the benefit incidence for program beneficiaries (i.e. targeting performance vis-à-vis the final funding allocations), but we know of no studies of decentralized CDD programs that decompose targeting performance into project applications and, conditional on application, selection. ${ }^{2}$

In this paper, we exploit a unique combination of datasets to examine the application and selection processes for a CDD project at the national and household levels. At the national level, we combine administrative data on the universe of project applications from villages and the final funding allocations to these communities under Tanzania’s Social Action Fund Second Phase (TASAF II) with a poverty map of Tanzania, as well as census data and voting records to distinguish the pattern of project applications from that of final spending allocations in almost

\footnotetext{
1 In this paper, we use pro-poor to mean that the share of per capita program spending that reaches poor communities (or households) is significantly higher than that for the non-poor. For a discussion of commonly used targeting performance measures, see Ravallion (2009).

${ }^{2}$ Coady and Parker (2009) pose a similar question in a different context, and assess the relative contributions of selfselection (i.e. applications) and administrative targeting (i.e. eligibility criteria) at the household level to the final targeting performance of Oportunidades, Mexico’s urban cash transfer program.
} 
2,200 wards. $^{3}$ We also examine the roles played by the center and the decentralized administrative units by decomposing these outcomes into within- and between-district components. Finally, we complement this analysis with micro level data from 100 program villages to assess awareness of TASAF II and the likelihood of benefitting from it at the household level. Using data on every household in these 100 communities, we examine the roles of eligibility, access to information, and political connectedness in determining beneficiary status in great detail.

We uncover a regressive pattern on the demand side: richer districts produce substantially more applications per capita than poorer ones at the national level while richer households are more likely to be aware of the program among those eligible at the local level. At both of these levels, independent sources of data paint a consistent picture: access to media, education, and political participation are strongly associated with the likelihood of being aware of and applying for projects.

Faced with this regressive pool of applicants, TASAF successfully utilizes several tools available to it to produce an ultimately pro-poor program. First, the effect of an inordinately large number of applications from richer districts is nullified by a funding formula that is used by the center to allocate each district a fixed amount of funds before the start of the program. Second, households eligible to receive grants for income generating activities under TASAF II determined by criteria also imposed by the center using easily observable household characteristics - are significantly more likely to be poor than ineligible households. Finally, even though eligible households who are aware of the program, i.e. those who can de facto apply for grants, are no more or less likely to be poor than other households (because program awareness increases with income), the selection process within districts is such that the final beneficiary pool is slightly poorer than the population as a whole. The final targeting performance can thus be decomposed into a strongly regressive demand-driven component, and then a funding formula, an eligibility rule, and a decentralized beneficiary selection process each of which is progressive.

In the end, however, the targeting performance of this CDD program, in which communities and households have to produce applications to receive government support and local authorities select beneficiaries under rules imposed by the center, is underwhelming. At the

\footnotetext{
${ }^{3}$ The hierarchy of administrative units in Tanzania is Region, District, Division, Ward, and Village.
} 
national level, a one standard deviation increase in poverty headcount would imply an increase of $\$ 0.24$ in per capita spending in the ward. ${ }^{4}$ Similarly at the household level, TASAF II beneficiaries are only marginally more likely to be poor than non-beneficiaries (in our household data $66 \%$ of TASAF II VG group members are poor, while 55\% of non-beneficiaries are). At both levels, these figures appear closer to a neutral targeting scheme (in which every ward or household receives the same amount of funding) than to a perfectly pro-poor allocation of funds. Furthermore, political activity at the ward level (measured by voter turnout) and proximity to the village center, political participation, connections to local elites, and access to other safety net programs at the household level are strong correlates of beneficiary status - even after controlling for poverty. Because program awareness is low among poor eligible households, a large fraction of the population - those who are most likely to be isolated and least likely to have access to other forms of safety nets - are left with no chance of receiving support from the program once the applications are in.

There are several takeaway messages from our study. First, even (or perhaps especially) in decentralized programs, careful centralized design is critical. The allocation of funding to subnational units and the designation of eligibility criteria provide direct levers for the center to influence the composition of beneficiaries. ${ }^{5}$ Second, our study provides guidance on how the very definition of sub-national administrative units and the appropriate choice for the level of decentralization can improve targeting: if the regressive pattern of applications is spatially clustered (as it is here), then defining sub-national units such that most of this variation is between units and then funding them using a predetermined formula will neutralize this effect.

\footnotetext{
${ }^{4}$ The increase of $\$ 0.24$ is calculated by multiplying the standard deviation of the poverty headcount $(0.184$ as shown in Table 1) with the coefficient estimate of poverty headcount on final per capita spending (1.33 as shown in column 6 of Table 2), i.e. $0.184 \times \$ 1.33=\$ 0.244$. By contrast, a ward with a poverty headcount of 0.34 , which is equal to the average headcount rate in our data across 2,177 wards, is expected to receive, on average, \$3.07 per person in TASAF II funding.

${ }^{5}$ Several empirical papers have attempted to measure the relative performance of national and local-level governments in poverty targeting (Ravallion, 2000; Alderman, 2002; Galasso and Ravallion, 2005). Mansuri and Rao (2012), summarizing the evidence on the performance of the central vs. the local authorities in allocating private transfers, find that such programs are mildly pro-poor at best with the targeting performance slightly better at the local level. In contrast, studies of social funds indicate that while the center is somewhat successful in allocating resources to poor areas, it is less successful in ensuring that poor households (or poorer communities within these poor areas) benefit more from these programs (Paxson and Schady, 2002; World Bank, 2002). For example, Paxson and Schady (1999) found in Peru that "there was no intra-district targeting." Targeting performance, especially at the center and the district levels, depends largely on the availability of data and the political will to use those data to target poor areas. For example, Galasso and Ravallion (2005) report that all 490 Thanas (sub-districts) in Bangladesh benefited from the Food-for-Education program because of political considerations and note that this is not uncommon.
} 
The same principle also applies to the spatial composition of poverty: progressive allocation of funds to districts will, on average, be more effective in channeling funds to the poor when poverty is explained mostly by income differences between districts rather than within them. ${ }^{6}$ As the starting point for any demand-driven program is the act of applying, a robust information campaign seems to be a necessary, but likely insufficient, condition for potential beneficiaries to join what is intended to be a participatory process. Our results suggest that informationally and politically marginalized groups start at a disadvantage when development is demand-driven.

The primary argument that has emerged from the literature so far as to why CDD programs fail to reach the poor is the idea of elite capture (Bardhan and Mookherjee 2000, 2005). A number of studies have examined the differences in policy preferences across elite and nonelite groups (Platteau and Gaspart, 2003; Rao and Ibanez, 2003; Dasgupta and Beard, 2007; Olken, 2007) and the role of local inequality in permitting elite capture (Conning and Kevane, 2002; Galasso and Ravallion, 2005; Araujo et al., 2008). When community development funds are used for political purposes they can also influence targeting performance (Cox and McCubbins, 1986; Dixit and Londregan, 1996; Schady, 2000; Khemani, 2010), while corruption can divert scarce resources away from their intended targets (Reinikka and Svensson, 2004). Most relevant to this paper, local political elites can steer funds towards themselves, their extended families, kinship networks, and constituencies (Arcand et al., 2006; Besley et al., 2007; Camacho and Conover, 2011). Alatas et al. (2013), using a recent experiment in Indonesia, find that local officials and their relatives, who are slightly richer than non-elites, are more likely to receive benefits than non-elites but also that the welfare losses from such elite capture are small.

However, the strong roles played by access to information and political involvement in our data raise the possibility that a different form of capture, an informational one, is at play. Such asymmetries in access to information are potentially welfare reducing even when local authorities are better able to take advantage of idiosyncratic information at the local level (Alderman, 2002), or when their priorities or their definition of who is poor, vulnerable, or deserving of social assistance are different than those of the center (Alatas et al., 2012). In practice, social funds typically engage in promotion campaigns to try to disseminate information

\footnotetext{
${ }^{6}$ Note, however, that Ravallion (2009), studying the relationship between traditional targeting performance indicators and poverty reduction in China's Di Bao cash transfer program, finds that the correlation between targeting performance and poverty reduction is low at best and recommends focusing on estimable outcome measures that are most directly relevant to the policy problem at hand.
} 
about the availability of funds and program rules as broadly as possible. Many also provide outreach (and facilitation) to help poor communities through the project application process (World Bank, 2002). Existing evidence on the effects of widespread dissemination of information suggests that such sensitization efforts should reduce capture (Francken et al., 2009; Reinikka and Svensson, 2011; Shankar et al., 2011). ${ }^{7}$

However, further inspection suggests that such sensitization can be subject to perverse incentives. If, for example, central or district level officials rely on local leaders and/or elites to promote these programs, they may be reluctant to spread the word extensively in order to steer benefits towards themselves, their extended families, kinship networks, or individuals with whom they have patron client relationship - creating a conflict of interest. Such conflicts of interest are likely to be felt most strongly at the local level when sensitizers are themselves potential beneficiaries and when the beneficiary pool is small. This reasoning suggests that even in the case of sensitization, centralized implementation or incentive compatible structures may be needed to neutralize the potentially regressive nature of demand-driven development. ${ }^{8}$ Our results suggest that demand-driven programs are unlikely to achieve real progressivity without a major effort in this direction, when large portions of the population lack access to information and to local elites or government officials. ${ }^{9}$ We return to a discussion of this issue in the concluding section.

The remainder of the paper is structured as follows. We describe TASAF II in more detail in Section 2, and then discuss the data and the estimation strategy in Sections 3 and 4. We present our findings at the national and the local levels in Sections 5 and 6, respectively, and Section 7 concludes.

\footnotetext{
${ }^{7}$ Coady and Parker (2009), studying the targeting performance of Mexico's Oportunidades program, find that the knowledge of the program decreased with increased per capita consumption, implying that the government's efforts in disseminating information about eligibility was successful. They find that the information campaign was instrumental in reducing coverage among richer households but had little role in increasing the concentration of transfers among the poorest households.

${ }^{8}$ Ravallion (2000) describes improvements in Argentina's Trabajar II program due to a reallocation of resources across provinces using provincial poverty indicators while also giving incentives to provinces for reaching the poor. Olken (2007) finds that while central audits significantly reduced corruption in road construction projects in Indonesia, community monitoring had negligible effects. Kochar et al. (2009) find that central mandates could be effectively used in the North Indian state of Punjab to target funds towards public goods primarily used by the poor. Dutta et al. (forthcoming) finds that awareness of right to work and how to get work is also low in India's National Rural Employment Guarantee Scheme and suggest using enhanced administrative capacity to improve local public awareness of the rights and rules of the scheme, as well as social audits for local monitoring.

${ }^{9}$ See Labonne and Chase (2009) for similar evidence from the Philippines.
} 


\section{Tanzania's Social Action Fund Second Phase (TASAF II)}

TASAF II is a USD 120 million social funds program - fairly typical of such large programs in Sub-Saharan Africa. In this second phase of TASAF projects, up to one third of all Tanzanian villages were expected to receive a sub-project by the end of 2010. TASAF II features three components: Service Poor (SP), Food Insecure (FI), and Vulnerable Groups (VG). Our analysis at the national level includes the universe of projects in all three components of TASAF II. The Service Poor component mainly provides public goods in the form of infrastructure projects, while the Food Insecure component is a workfare program, in which very low daily payments are mostly self-targeted among able-bodied individuals. ${ }^{10}$ Our analysis at the national level includes all three components. Because the VG program has a particularly well-defined beneficiary group and provides excludable private benefits, we focus on this sub-component in our analysis of the effect of eligibility rules on the targeting performance of the program at the household level. The beneficiaries of VG projects are 'vulnerable' households, i.e. those containing elderly individuals, people with disabilities, widows, orphans, and those affected by HIV/AIDS, who form small groups and receive grants for income generating activities. ${ }^{11}$

Application and awareness in this CDD program are each outputs of a complex institutional process. Local government officials initiate project applications, but a successful application must pass technical review by district-level officials and, in the case of VG applications, must include an informed and eligible beneficiary group. Villages that do not apply cannot receive funding. Similarly, knowledge of the program is the primary responsibility of the sensitization conducted at the beginning of the program by district and local government officials, but individuals who do not participate in village information dissemination activities

\footnotetext{
${ }^{10}$ However, in lean season, the demand for these low-paying jobs can be high enough to warrant rationing at the local level. In such cases, communities come up with lists of able-bodied individuals who are eligible to benefit from these local workfare projects.

${ }^{11}$ Vulnerable Groups projects provide grants of US\$6,000-10,000 to groups of roughly 10 individuals from vulnerable households in order to finance an entrepreneurial activity. Typical activities for these groups are animal husbandry, beekeeping, tailoring, or the operation of milling machines. These projects thus generate an unusually private form of benefit relative to typical CDD programs. Anecdotal evidence collected by the authors suggests that the formation of these groups across study villages is not uniform. In some cases, pre-existing groups (such as a selfhelp group) can apply to receive funding under this component; in others, newly-formed groups seek to receive funding; yet in other cases, village chiefs help form vulnerable groups (by grouping the elderly or widows or disabled together) and propose the income-generating activity (hence providing coordination across groups and income-generating activities within the village). In all cases, applications must have the explicit approval of the village executive officer before being submitted to TASAF.
} 
will be difficult to reach. Those who are unaware of the existence of the program will not be included as beneficiaries, even if they qualify.

District- and village-level officials are the key actors in this decentralized setting. The well-defined roles for different actors in the TASAF II funding process give us the ability to differentiate the effects of their actions. Here, we describe the project selection process in detail by providing the 'waterfall' of steps through which a proposal must go and linking each layer of decision-making to a specific part of the empirical analysis. As with many such decentralized programs, the funding waterfall features a mixture of centralized design features with decisionmaking at lower administrative levels, with clearly distinguished roles for national and subnational actors. The initial decisions in this waterfall, illustrated in Figure 1, are two key centralized features: the eligibility rules for the program, and the formula that will be used to distribute funding across sub-national units, i.e. districts in the case of Tanzania.

The allocations from the center to the districts under the predetermined funding formula were based on a weighted score calculated using three variables: population, geographical size, and a poverty index. The poverty index used by TASAF II administrators was based on indicators of access to basic social services such as health, education and water. It also included variables, such as food security, disability, number of orphans, and the HIV/AIDS burden in the district. ${ }^{12}$ Still, since using funding formula alone could result in large differences between district councils' allocations, 25\% of the National Village Fund (NVF, the main spending vehicle under TASAF II) was first distributed equally to all councils. The remaining amount was then distributed using the funding formula described above.

In order to initiate the possibility of funding, village officials work with TASAF district officials to sensitize the local population as to the existence and nature of the program, and then village officials must complete an application, called a sub-project interest form or SPIF, to the program. TASAF II created an elaborate screening process in order to guard against the types of elite capture documented in other community development programs. Recognizing the importance of outreach in this process, every one of Tanzania's 11,000 villages were supposed to be visited by an official from the district and given information about the program and how to

\footnotetext{
12 The data used came from NBS (HBS, Demographic and Health Survey), Ministry of Agriculture and from administrative data that were gathered from each Local Government Authority. This funding formula is only weakly correlated with the measure of consumption poverty used in this paper once we control for district population and area size.
} 
apply. TASAF district officials then work with the key village level officials (the Village Executive Officer and Village Chairman) to receive applications from villages that choose to pursue funding. The application is forwarded through the district TASAF office to be registered at the central offices in Dar es Salaam, the capital of Tanzania. This is the definition of 'application' in our data.

Once an application is registered, it is then subjected to an evaluation process by districtlevel TASAF officials and by the elected District Council. First, it goes through a 'technical review' by district-level sector experts. Promising proposals are then subjected to an 'extended participatory rural appraisal' (EPRA) by trained TASAF facilitators, a village meeting during which they undergo a business plan and budget review, an environmental review, and a pairwise ranking exercise that guarantees that the project applied for is indeed the one desired by the community. ${ }^{13}$ Because an initial application only specifies the project type and the village, the participatory appraisal may result in the clarification of or changes to the intended nature and scope of the project, as well as the identities of beneficiaries as appropriate. ${ }^{14}$ The beneficiaries of Vulnerable Groups project applications are finalized at this stage. ${ }^{15}$ Surviving proposals are then sent to District Council's Finance Committee (a non-TASAF political entity at the district level) for final selection. ${ }^{16}$ The center plays no role whatsoever in this selection process, and disburses funding once the districts have decided which projects they would like to undertake within the budget they had been allocated from the center.

The clean segregation of this decentralized program into a formulaic cross-district component and a complex decision-making process within districts provides us with a particularly exact econometric analogy. The between-effects regression on spending per person across districts recovers the final effective spending progressivity as determined by the cross-

\footnotetext{
${ }^{13}$ In the pairwise ranking exercise the whole village is called to a meeting, divided into groups by demographics, asked to come forward with a number of different project suggestions, and then village votes on pair-wise combinations of these potential projects. If the outcome of this exercise is different than the application the village has submitted, then the village is expected to go back to the drawing board and submit another application that is in line with the participatory appraisal. However, TASAF officials, through email communication with the authors, suggest that such cases were extremely rare.

${ }^{14}$ A SPIF for a VG project contains minimal information, usually the vulnerable group (such as widows or elderly) and the proposed income-generating activity (such as animal husbandry or tailoring). It does not include a list of beneficiaries. Hence, the list of beneficiaries for this component is finalized during the village meetings that take place as part of the EPRA process.

${ }^{15}$ While a trained facilitator from the TASAF District Office conducts the EPRA, the decisions regarding the details of the project and, where relevant, list of beneficiary households are meant to be made through a participatory discussion.

${ }^{16}$ The District Council is composed of elected councilors from each ward.
} 
district funding allocation at the national level. All within-district targeting of spending, then, is the sole product of the decentralized district-level bureaucracy of TASAF working in concert with village-level officials under the eligibility constraints imposed by the center. Figure 1 provides a detailed schematic of the roles played by different actors in the sensitization and screening process, and the regression analysis that corresponds to each step in the waterfall.

\section{Data}

\subsection{Poverty maps}

We construct the national database beginning with a poverty map created by the authors using the method described in Elbers et al. (2003). This exercise uses the household surveys from Tanzania’s 2000/01 Household and Budget Survey (HBS) and the 2002 Population and Housing Census, both conducted by the National Bureau of Statistics (NBS). The HBS is a nationally representative sample of 22,178 households sampled between May 2000 and June 2001. The HBS is a much richer survey than the population census, containing information on a wide range of outcomes including demographics, education, health status, and ownership of durable assets, and most importantly a measure of per capita household consumption. However, the HBS is cluster-sampled and hence cannot be used to understand poverty in every sub-region of the country. The small area estimation technique used here allows us to be able to construct poverty estimates for smaller geographic units of aggregation, such as districts or wards. ${ }^{17}$ Poverty rates were estimated at the level of each ward on the basis of a methodology that is described in detail in Elbers et al. (2003). PovMap 2.0 was used to estimate poverty rates and their standard errors for the wards and districts of Tanzania. ${ }^{18}$ We estimate poverty based on a measure of per capita household consumption, which is estimated using the HBS, with the set of explanatory variables restricted to those that are also found in, and strictly comparable to, the population census. We then use these estimates to calculate the poverty rate of wards and districts in the population census using the vector of parameters from this model, including those that describe the distribution of the disturbances. Using this procedure, our estimate of the poverty headcount differs from its true value due to two types of errors: idiosyncratic error, which is due to the unobserved component of household consumption and declines rapidly with the size of the

\footnotetext{
${ }^{17}$ The poverty mapping data are missing for the islands of Zanzibar and Pemba, and so we restrict our analysis to mainland Tanzania.

${ }^{18}$ See iresearch.worldbank.org/PovMap/ for documentation of the software for poverty mapping.
} 
target population; and model error, which is due to the fact that the true (unknown) parameters of the model are estimated. ${ }^{19}$

Because estimating our regressions using a predicted rather than observed value of poverty rate as an explanatory variable would typically underestimate the true variance of the coefficient estimate for poverty, we follow a simulation procedure very similar to that suggested by Elbers et al. (2005). We utilize poverty estimates from the underlying simulations conducted in PovMap that explicitly include all three types of error. ${ }^{20}$ We bootstrap standard errors for all regressions using poverty estimates as an explanatory variable, iterating 500 times and for each draw selecting both a new poverty estimate and sampling with replacement from our own data. This bootstrap distribution thus contains all three sources of error in the poverty map estimates as well as the downstream sampling error.

\subsection{Institutional Data from TASAF II}

This paper utilizes two main databases from the management information system (MIS) of TASAF II. The first contains every application received by TASAF II between May of 2004 and October of 2007, for a total of 102,606 applications. More than 95\% of the 2,542 wards in mainland Tanzania submitted at least one application, with the median ward submitting 14 . This application, called a sub-project interest form (or SPIF), constitutes the first step in seeking TASAF II funding and records only the location, beneficiary group, and sector of the project but specifies neither the amount of funding requested nor a list of the would be beneficiaries. The second institutional database describes every TASAF II project funded through August 2008, and gives details of the beneficiaries, project type, and budgets for each of the 4,037 projects funded. This database also shows the composition of funding provided by the NVF, local government authorities, and the community itself. NVF spending typically makes up about 80\% of total project costs, and is never below $50 \%$. We merge these datasets at the ward level to calculate the number of applications, the percentage of applications funded, and the total amount spent from each source per ward.

\footnotetext{
${ }^{19}$ A third type of error, namely computation error, is made negligible through a sufficiently large number of simulations.

${ }^{20}$ The average of the poverty rate for each administrative unit across these simulations yields the poverty mapping estimate for that unit.
} 


\subsection{Electoral Data}

The electoral data used in the national analysis are from the 2005 presidential election. All data are available online at the website of the National Electoral Commission of Tanzania. ${ }^{21}$ The presidential results are at the constituency level ${ }^{22}$, and the electoral data is merged with the TASAF II institutional data and the poverty maps as a weighted average vote by the constituencies overlapping each ward (weighted by fraction of surface area of the ward in each constituency). The elections took place prior to the announcement of the awards of TASAF II projects, and hence we take political outcomes as predetermined, and seek to understand how voter registration and turnout, as well as voting patterns, relate to application, approval, and funding patterns. We calculate two core political variables: ward-level votes as a fraction of population, a variable that combines voter registration and turnout and serves as our measure of political engagement. For brevity, we refer to this variable as 'turnout.' The second indicator is the share of the electorate that voted for the dominant Chama Cha Mapinduzi (CCM) candidate Jakaya Kikwete. This variable is intended to measure patronage; the extent to which programs may be targeted at core or opposition regions.

\subsection{Household Survey Data}

The household survey data were collected in 2008 as a part of a cluster randomized impact evaluation of the Vulnerable Groups component of the project conducted by the authors. First, five districts were selected: Moshi, Kwimba, Lushoto, Makete, and Nzega. ${ }^{23}$ Then, within these districts the TASAF district officials, who are called village fund coordinators or VFC, were asked to take the first 20 villages in which VG projects had been newly approved (but project funds not yet disbursed), and these villages were then enrolled in the study. This sample of 100 villages is explicitly not a representative sample of villages even in these five districts (because every one of them would receive a VG project), but may be considered as representative of the types of villages that are selected for VG funding.

\footnotetext{
${ }^{21}$ Data available from http://www.nec.go.tz/

${ }^{22}$ The constituency is a region defined for electoral purposes. The 232 constituencies in Tanzania are typically larger than a ward but smaller than a division.

${ }^{23}$ These five districts were intended to give a broad representation of the 119 districts in mainland Tanzania as a whole. Compared with the average poverty headcount in Tanzania, our estimates suggest that poverty rates are lower than average in Lushoto and Moshi, roughly average in Nzega, and slightly higher than average in Kwimba and Makete. They were selected for inclusion in a cluster randomized impact evaluation of the vulnerable groups component of TASAF II with the help of TASAF officials and it is important to note that they were not selected randomly from the list of all districts in Tanzania.
} 
We then conducted a comprehensive study of this sample of 100 villages. First, we conducted a listing exercise that gives us a census of all 61,611 households in these communities. The short listing survey collected basic demographic information about the household (e.g. household size and age of the eldest household members), GPS data (allowing us to calculate distance to village center for every household), and determined whether or not the household contained a vulnerable, i.e. eligible to receive funding from a VG project, individual. This information allowed us to sort households into four strata for the study: village elites (Village Executive Officer or Village Chairman), TASAF II VG beneficiaries, eligible nonbeneficiaries (households that contain a vulnerable individual but do not benefit from the program) and ineligible households. At the time of the listing exercise, the person answering the survey was also asked whether he or she was familiar with TASAF. This question provides the data that underlies our 'heard/aware of TASAF' indicator. ${ }^{24}$

For the detailed household survey, the two village leaders and the three group leaders (chairperson, secretary, and treasurer) were always sampled with probability equal to 1 . In addition, three other VG beneficiaries, three eligible non-beneficiaries, and three ineligible households were randomly sampled to produce a sample of 14 households in a typical village with only one TASAF II VG project awaiting funding for an income generating activity - or a final sample of 1,544 households in 100 study villages. ${ }^{25}$ The main advantage of the household survey sample for this study is that it contains detailed consumption data at the household level allowing us to construct a poverty measure based on a comprehensive consumption aggregate. The effort to carefully stratify the sample into beneficiaries, eligible non-beneficiaries, and ineligible households and collect data from all of them allows us to rigorously analyze the targeting performance of the program at a very micro level. These data form the basis of our analysis of targeting performance in Table 4.

As the household survey sample was relatively small, all households with vulnerable members (including VG beneficiaries and eligible non-beneficiaries - 38,871 households in total), and a large randomly selected sample of ineligible households were also given a long listing survey. This survey was significantly shorter than the household survey and, importantly,

\footnotetext{
${ }^{24}$ Since the vulnerable individual in a household may or may not have been the one answering the listing survey, this question does not provide a perfect measure of the information among the eligible individuals, but provides a reasonable proxy for the extent to which the existence of the program was understood in the household as a whole.

${ }^{25}$ The sample size is larger than $1,400(14 \times 100)$ because some villages had more than one VG project.
} 
did not collect detailed consumption data in each household. However it collected limited data on consumption of proteins (number of days fish, meat, or eggs were consumed), education of the household head, asset ownership, participation in village meetings, whether household members hold political office in the village, blood relationships between household members and village officials, and whether they benefited from other safety net programs. These data are used to analyze awareness of TASAF among eligible households and the determinants of being a program beneficiary among eligible households aware of TASAF in Tables 5 and 6.

In summary, two detailed databases are available for our study. The first one is a wardlevel database covering virtually all of mainland Tanzania to study targeting performance of TASAF II at the national-level. There are 2,542 wards in 119 districts in mainland Tanzania. The poverty mapping data is unavailable for 86 of these wards. Out of these, the ward councilor elections were uncontested in 254 wards, depriving us of any electoral outcome data other than the political party of the winner. The poverty maps cannot be calculated for an additional 25 wards, meaning that regressions using vote shares and turnout are conducted on the 2,177 wards for which both poverty and electoral data are available. ${ }^{26} 66$ of these wards submitted no applications to TASAF II, and so the analysis of the percentage of applications funded is conducted in 2,111 wards. The second one is a household-level database from the 100 villages with VG projects that allows us study benefit incidence within villages. Table 1 provides summary statistics on the ward-level sample in the left panel, and on the household-level sample in the right.

These two datasets provide us within an unusually comprehensive view of the benefit incidence of TASAF II all the way from the center to the household level. However, there are several important respects in which our data have limitations. First, we are unable to study the targeting of villages within wards because we are missing this link in the data chain. ${ }^{27}$ Second, while the ward is not a unit of great importance in the implementation of TASAF II, we use it as the unit for the national targeting analysis simply because it is the smallest unit at which our various national databases can be merged. Third, our study of within-village targeting focuses only on the VG component of TASAF II and not on the Service Poor or Food Insecure

\footnotetext{
${ }^{26}$ Uncontested wards are slightly less likely to submit applications than other wards, but are not different in terms of poverty or funding than the contested wards included in the expanded analysis.

${ }^{27}$ Matching village names from SPIFs to census data would have been very difficult, if not impossible. Even if we could do this, we would not have poverty estimates at this level, nor would we have electoral data.
} 
components. The eligibility for the VG program, which provides private goods to households, is more clearly defined, hence making it easier to address the question of national- versus locallevel targeting criteria, but this limitation is important to note.

\section{Estimation Strategy}

Our estimation strategy is influenced by Galasso and Ravallion (2005), which provides an empirical structure for testing the additional contribution of local information gained through decentralization. In particular, they define the information set held by the central planners and then use a household dataset to construct a much richer definition of 'eligibility' for the program than was available to central bureaucrats. They then attribute the additional poverty targeting achieved above and beyond that coming from the planners' information set as the benefits arising from decentralized targeting. Our approach is inspired by this structure in the sense that the only components of TASAF II that were centrally dictated were eligibility rules, the allocation of funds to the districts, and some guidelines provided to the districts for the selection of subprojects and beneficiaries. Therefore most within-district targeting arises from the actions of decentralized agents. We therefore decompose the variation in targeting efficiency into a crossdistrict (centralized) and a within-district (decentralized) component. Using this structure, we can separately isolate the role of the clearly defined funding formula that drives allocation to the districts, and the complex decentralized process through which the districts allocate funding to the lower administrative levels.

Analyzing TASAF II applications received and final TASAF II spending per capita at the ward level, we present the univariate correlation between the headcount index and the outcome of interest and econometrically decompose this relationship into a between-district and a withindistrict component (Table 2). In Appendix Table 1 and Table 3, we present a multivariate linear regression using an additional set of controls to examine the underlying correlates of these outcomes. Specifically, for ward $i$ in district $d$, we estimate:

Within districts only: $\quad y_{i d}=\alpha_{d}+\beta_{1} P_{i d}+\beta_{2} X_{i d}+\beta_{3} Z_{i d}+\varepsilon_{i d}$

Between districts:

$$
\bar{y}_{d}=\beta_{0}+\beta_{1} \bar{P}_{d}+\beta_{2} \bar{X}_{d}+\beta_{3} \bar{Z}_{d}+\varepsilon_{d}
$$

Pooled OLS:

$$
y_{i d}=\beta_{0}+\beta_{1} P_{i d}+\beta_{2} X_{i d}+\beta_{3} Z_{i d}+\varepsilon_{i d}
$$


where $y_{i d}$ is one of the three outcomes of interest, $P_{i d}$ is the poverty headcount ratio at the ward level, and $X_{\text {id }}$ and $Z_{\text {id }}$ (used only in the specifications for Table 3 and Appendix Table 1) represent a broader set of socio-economic and political controls. Equation (1) is estimated with district-level fixed effects and hence is identified only by within-district variation at the ward level; equation (2) is estimated at the district level using district averages, and equation (3) pools these two sources of variation to estimate the total effect.

An important empirical issue relates to the estimation of the marginal effects of poverty when the right-hand side variable comes from a Poverty Map and hence is estimated with error. If the first-stage regression is the one that creates the poverty map estimate and the second stage regresses a final outcome on poverty, the standard errors in the second stage must reflect the prediction error in the first stage. We therefore conduct 100 runs of the poverty map, each time drawing a new set of model parameters and estimating a new predicted log per capita consumption figure for each household in the population census. This provides us with 100 replications of the poverty estimate that contain the idiosyncratic and model error. We then collapse these 100 estimates to the appropriate unit for analysis (ward or district), merge them with our institutional data from TASAF II, and then resample with replacement 500 times, each time randomly selecting one of the 100 poverty simulations. The distribution of the resulting marginal effects contains both the first stage and the second stage regression error, and the standard errors reported in all regressions are calculated from the distribution of these bootstrapped coefficients.

We construct two core dependent variables for the ward-level analysis. The first indicator is the number of applications submitted from a ward per 1,000 individuals. Fewer than 5\% of wards submitted no applications, with a median of 1.2 and a mean of 3 applications per thousand people. $^{28}$ The second dependent variable is the per capita spending in US dollars in each ward, which is used to measure the incidence of transfers under the program. To support this analysis, we also examine the fraction of applications that are approved in Table 3 and Appendix Table 1. This is an outcome defined only for wards that submitted at least one application, thus we lose the 67 wards from our analysis, from which no applications were made.

\footnotetext{
${ }^{28}$ The average number of applications submitted by villages is 39 per ward and 834 per district.
} 


\section{National Targeting Performance using Ward-level Data.}

The national incidence of applications and spending are presented in Table 2. Columns (1-3) demonstrate that the number of applications emanating from a ward decreases strongly with its poverty rate. The coefficient estimate in column (3) indicates that moving from a ward at the $25^{\text {th }}$ percentile of poverty headcounts to one at the $75^{\text {th }}$ percentile (moving from a poverty headcount rate of $19 \%$ to $46 \%$ ) would predict a decrease of approximately 1.3 applications per thousand inhabitants - equivalent to 0.25 standard deviations. Interestingly, column (2) suggests that this effect is almost entirely due to the fact that more applications come from richer districts. This much stronger cross-district variation indicates that a similar increase in poverty would decrease the expected number of applications per thousand by 2.8 , or by more than 0.8 standard deviations.

While applications are strongly regressive with respect to district-level poverty levels, we find no evidence that poorer wards submit fewer applications within districts (column 1). This statistical distinction proves to be consequential given the unit of decentralization in Tanzania: the center is responsible for allocating funds to each district, while district officials are responsible for targeting within each of these units. As TASAF II allocations to districts are predetermined using the center's funding formula, applications from districts with higher application rates will mechanically have lower probabilities of success. ${ }^{29}$ It is therefore significant that despite the large cross-district regressive pattern in application rates, applications are orthogonal to poverty status within districts. This indicates that predetermined funding to districts will have nullified the regressive nature of the applicant pool, which would have been the job of district officials had applications been coming primarily from richer wards within districts. We return to this point later in this section.

To examine the final incidence of spending under TASAF II, we turn to columns (4-6) of Table 2. The within-district targeting incidence is mainly the responsibility of the decentralized agents in TASAF. Column (4) shows that these decentralized actors prove successful in targeting spending within their districts: the final spending per capita increases with the poverty headcount

\footnotetext{
29 This can be seen in Columns (1) and (2) of Appendix Table 1, which shows that just as applications were much more likely to come from richer districts, applications in such districts were much less likely to get funded. Figure 2 shows this inverse relationship between number of applications per capita and funding probability at the ward level. This finding is also suggestive that the heterogeneity in applications is not simply arising from the expected probability of funding: application rates are highest in places where the success rates are lowest and vice versa.
} 
ratio in the ward. This effect is sufficiently large as to drive the total incidence seen in column (6), which indicates that the final spending per capita is pro-poor under TASAF II - even if mildly so. Column (5) shows that, despite the fact that the center's allocation formula included proxies of poverty, almost all of the pro-poor final spending is explained by variation within districts rather than between them. It seems that the central funding formula was successful in nullifying the potentially detrimental effect of a much larger number of applications from richer districts and left the job of steering funds to poor communities to the district governments. ${ }^{30}$

Hence, a strongly regressive pool of applications is turned into a progressive final incidence of spending by the combination of two forces: a central funding formula that nullified the strongly regressive and largely cross-district variation in application rates and a decentralized within-district selection process that pushed funds towards poorer wards. The marginal effects indicate that a ward going from being universally non-poor to universally poor would see spending per person increase by only $\$ 1.33$ from a base of $\$ 2.62$ (the lowest poverty headcount rates observed in the data is 0 , and the highest 0.986 ). In other words, a one standard deviation increase in the poverty rate of a ward (an approximately 20 percentage point increase in the headcount ratio) would cause an increase of only $\$ 0.25$ per person or approximately $\$ 3,300$ total in a ward of average population size. These results are typical of the broader literature on CDD that show benefit-incidences that are only moderately pro-poor. ${ }^{31}$

Before moving to an examination of within-district performance, we make a few more points on the role of between-district effects on project applications and selection. First, applications are more likely to be coming from districts with better access to media (measured by the fraction of households with a radio or phone) and with higher voter turnout - highlighting the role of information and political engagement in this demand-driven program (Appendix Table 1,

\footnotetext{
${ }^{30}$ Comparing the coefficient estimate in column 5 of Table 2 to that in column 4 of Appendix Table 1 indicates that the actual pattern of expenditures appears to be slightly more progressive than the budgeted pattern, meaning that deviations from the original spending plan may have served to make the program somewhat more pro-poor.

${ }^{31}$ Another way to consider why these estimates indicate a mildly pro-poor performance is by considering what the regression coefficients would be if the program were neutral (i.e. allocated its funds evenly per person) and under the extreme scenario of the program being perfectly pro-poor in the sense of allocations proportional to the headcount ratio. Compared with our estimates of a constant term equal to US\$2.62 and a coefficient estimate of 1.33, a neutral program would have allocated everyone US\$3.07 and produced a coefficient estimate of 0. A perfectly pro-poor program would have allocated no funds to areas with a poverty headcount of zero (i.e. the constant term would be equal to zero) and produced a coefficient estimate of 9.06. Hence, the final spending allocation per capita across wards that we find in Table 2 is fairly close to a neutral program.
} 
column 3). ${ }^{32}$ In Section 6, we will show that the correlates of awareness of the program at the household level are very similar and consistent with the evidence from these ward-level data. Similarly, the final allocations from the center are higher for districts with higher voter turnout (Appendix Table 1, columns 5 and 6).

Second, given that the unit of decentralization in Tanzania is the district, it would be hard for the center to improve its targeting performance without making significant changes in its procedures. The center could have given more weight to poverty in its funding formula, or implicitly used a higher inequality aversion parameter to give poorer districts more funds per poor person (i.e. treating equally poor households/communities in different districts differently), but given its decision to first allocate $25 \%$ of the NVF evenly across districts before using a mildly pro-poor formula to distribute the remaining funds, it seems likely that this may not have been politically feasible. ${ }^{33}$ The center could have also tried to give funding directly to divisions or wards, bypassing the districts, but administrative structure and low capacity at lower levels of government likely stood in the way of such an approach. Or, the center could have tried to give incentives to districts for poverty reduction (Ravallion, 2000). While the center's funding formula was simple and amounted to a little better than allocating equal amounts to districts per person and geographic area, it was still effective in nullifying the effect of an inordinately large number of applications from richer districts - even if this success may have been largely circumstantial and context-specific.

Third, just because the regressive pattern of project applications was across districts in the case of Tanzania rather than within them, it does not mean that we should expect the same pattern to be repeated elsewhere. An important feature of Tanzanian political geography is that the country has split urban areas from the surrounding rural areas to constitute their own districts. Of the 119 districts in the data, 14 cities have been split off from their surrounding districts to form separate urban and rural districts. ${ }^{34}$ The 14 urban districts plus the major city of Dar es Salaam comprise only $3.6 \%$ of the area and $13 \%$ of the population of the country, and yet make

\footnotetext{
${ }^{32}$ For purposes of comparison, the intra-district correlation in applications per capita is very similar to that of poverty itself (0.354) and of voter turnout (0.308). On the other hand, it is substantially lower than that of ownership of radio or phones $(0.614)$, which is presumably increased by the clustered nature of radio and phone mast transmitters.

33 As mentioned before, Galasso and Ravallion (2005) report that all 490 Thanas (sub-districts) in Bangladesh benefited from the Food-for-Education program because of political considerations and note that this is not uncommon.

${ }^{34}$ This pattern is different from neighboring countries such as Uganda or Kenya, where only the two largest cities of Nairobi and Mombasa are set in their own districts.
} 
up almost a third of the total applications to TASAF II. While it is possible that all urban areas simply had superior district-level TASAF II sensitization processes, a more likely explanation is the greater access to information and government bureaucracy are responsible for the higher demand. In a different setting where the regressive nature of the applications was due to variation within the units of decentralization rather than across them, local officials would have had to work harder to channel funds to poorer areas without the benefit of a predetermined funding formula based on detailed information on each constituency.

Before concluding the targeting analysis at the national level, we return to a more detailed examination of targeting performance within districts. In Table 2, we showed that while per capita applications within districts are uncorrelated with the poverty level of the wards, final per capita spending is higher in poorer wards. Table 3 examines, within districts, the correlates of applications received per 1,000 people from each ward (column 1), spending per application (column 2), and final per capita TASAF II spending in each ward (column 3) by adding covariates to the same specification used in Table 2 (columns $1 \& 4$, respectively). Column (1) shows that the number of applications per capita from wards within districts is as good as random, reinforcing the earlier finding. None of the variables we include in our regression model is significantly associated with the number of applications per capita. In response, districts seem more likely to select applications coming from more rural wards (column 2), although this relationship is not statistically significant. Column (3) suggests that final spending is channeled towards wards that are rural and sparsely populated - consistent with the aim of social funds to reach such areas that are usually underserved in terms of service delivery. However, even within districts, the pattern of wards with higher voter turnout receiving more funding per capita remains. Thus the district- and local-level actors overall achieve a funding incidence that is progressive in education and pushes money towards rural and sparsely-populated wards (which therefore have poor access to radio and mobile phone networks), but remains regressive in political involvement at the ward level (voters/population). ${ }^{35}$

\footnotetext{
${ }^{35}$ Appendix Table 2 presents some robustness checks on our analysis of the ward-level data. Panel A presents findings when poverty headcount is replaced by the poverty gap. While the point estimates increase (because the units of the dependent variable change) the interpretation remains the same. Panel B addresses the concern that division bias may be pushing our coefficients upwards if population were measured with error (Borjas, 1980). While we use a population census to measure this variable, which reduces the likelihood of measurement error, we first control for the inverse of population, the quantity in which error may enter the equation. The purely between-district regressive nature of applications remains with this control, but the per-capita funding no longer appears progressive. Given that funding favors sparsely populated districts and wards, the control for inverse population effectively takes
} 
These results provide national evidence of a theme that manifests itself in very similar ways in the household-level analysis that follows: demand-driven community development projects put the onus on local actors to pull funding towards themselves. They therefore face the danger of rewarding constituencies that are more informed, mobilized, and capable of overcoming collective action problems to successfully seek funding.

\section{Targeting Performance at the Village Level}

To examine the targeting performance of the program at a very micro level we selected a sample of 100 villages in five districts, which had just been chosen to receive TASAF II funding (but had not yet received these funds). We used a comprehensive listing exercise to enumerate each household and collected detailed data for a stratified random sample of households that is representative of village elites, program beneficiaries, eligible non-beneficiaries, and ineligible households before any VG funds were disbursed in these study villages. To isolate within-village effects, we use village-level fixed effects in the analysis that follows. ${ }^{36}$

The national bureaucracy still has some influence at this level, mainly in setting the eligibility criteria for the program. In order to study a well-defined 'eligible' group, we focus on the Vulnerable Groups (VG) component of TASAF II. This program had clearly articulated household-level eligibility rules and thus permits a direct examination of this central targeting component. At the same time, such rules will only have bite (and result in a progressive final beneficiary group) if the decentralized bureaucracy is willing and able to enforce them. So it is interesting to consider both the de jure eligible group relative to the population, as well as the de facto comparison of the beneficiaries to the nominally eligible.

We use the household data to conduct a village-level targeting analysis with as close a parallel as possible to the national-level analysis. Just as the central government controls the cross-district funding formula, it controls the de jure eligibility. Analysis of the targeting of eligibility itself therefore isolates the role of the center. The sensitization and selection of actual beneficiaries within this eligible population is the responsibility of decentralized actors. As with

the regression out of per capita units. TASAF II gives a similar sum of money to each ward, meaning that poor wards are overfunded only on a per-capita basis. This can be seen more clearly in Panel C, where we move completely out of per-capita terms and regress the total spending per ward on the population and the poor population per ward. Again, in absolute terms TASAF II applications are regressive and the funding process is very weakly propoor across wards.

${ }^{36}$ We have also conducted all of the regression analysis in this section using ward-level fixed effects. The results are very similar and can be obtained from the authors upon request. 
the role of applications at the national level our study introduces an empirical measure of the ‘demand-driven’ component of CDD programs. The same sensitization campaign that solicits applications must first 'spread the word' so that eligible individuals come into the project pipeline as potential beneficiaries. In practice, universal awareness of this new program did not occur, and our results indicate that the requirement that individuals have to produce applications again proves regressive.

Our analysis of within-village targeting makes use of baseline data collected for a randomized evaluation of the VG projects that was designed to assess their impact on the creation of small enterprises and improvements in household welfare. We begin the analysis of the household-level data by analyzing the sample of households with detailed survey data. These data allow us to calculate household-level consumption aggregates, and therefore to conduct an analysis of poverty at the local level. We use sampling weights to make this sample representative of the population in the 100 study villages.

Figure 3 shows the cumulative distribution function (CDF) of monthly per capita consumption among the entire population of these 100 villages, all eligible non-beneficiaries, eligible households who heard of TASAF, and VG project beneficiaries. ${ }^{37}$ The figure shows that while the eligibility criteria for this program is progressive (eligible non-beneficiaries are poorer than the population as a whole; p-value $=0.028$ for the Kolmogorov-Smirnov, K-S, test for the equality of distributions), eligible households who are aware of the program's existence have roughly the same distribution function as the average household in these villages (K-S pvalue $=0.115$ ). Furthermore, the final group of VG project beneficiaries is not significantly poorer than eligible non-beneficiaries (K-S p-value $=0.424){ }^{38}$ These observations indicate that the progressive eligibility criteria imposed by the center is set back by lower program awareness among the poor and that conditional upon eligibility, the selection process at the local level does not produce a poorer group of beneficiaries. Again, the combination of eligibility criteria from the center (vulnerability) and the within-village selection process produces a targeting performance that is mildly pro-poor at the local level: VG beneficiaries are 10 percentage points

\footnotetext{
${ }^{37}$ Note that this figure includes comparisons across villages, and hence does not isolate the within-village targeting component as the regressions in Tables 4-6 do.

${ }^{38}$ The VG project beneficiary status employed in this analysis is defined using in-depth group surveys of each VG sub-project at baseline, i.e. after the sub-project was approved for funding (and the group informed) but before the disbursement of funds. The entire list of group members, i.e. beneficiaries, was enumerated during this group survey and their names and membership statuses (chairperson, secretary, treasurer, or member) were recorded. These were then linked to the listing data and the detailed household surveys used in this section.
} 
(pp) more likely to be categorized as poor than the average household in these villages using our lower-bound poverty line of 18,000 Tanzanian Shillings per month per capita in 2008 prices.

Table 4 analyzes receipt of the program in stages that isolate the roles of eligibility (dictated by the center) and the broad within-village process that subsumes the awareness and actions of potential beneficiaries and their selection as final beneficiaries. Column (1) examines the likelihood of being a TASAF II beneficiary among all households - the final product of the eligibility criterion, the application stage, and the within-village selection process. Poor households are 1.4 percentage points more likely to be VG project beneficiaries than non-poor households over a mean of $2.8 \%$ for the non-poor. Column (2) repeats these regressions using a richer set of covariates, and demonstrates that program beneficiaries live closer to the village population center, are more politically active (both in terms of participation and holding local office) and more likely to benefit from other social safety net programs designed for vulnerable households - compared to the entire population. Heads of beneficiary households also have lower levels of education.

The next four columns decompose this progressive selection of beneficiaries into two components: eligibility among all households and beneficiary status among eligible ones. Column (3) shows the de jure targeting rule, estimating the likelihood of being eligible for TASAF II VG projects by poverty status: poor households are, on average, 9.3 percentage points more likely to be categorized as eligible for the program. Column (4) indicates that the vulnerability criterion identifies a group that is poorly educated, with lower access to media and to village officials, rather than one that is poor conditional on these variables. Consistent with Figure 3, the nationally stipulated piece of within-village targeting is progressive.

A simple manipulation of the estimates in this table indicates that the probability of being a program beneficiary is the same for those categorized as poor and the non-poor among those who are eligible. This is confirmed by the analysis in column (5), which shows that poverty status is not correlated with beneficiary status among the eligible. Column (6) indicates that household heads in beneficiary households have significantly higher levels of education relative to eligible households - in contrast to the finding that they are less educated compared with the average household (column 1). They are also, exactly as in column (2), more likely to live closer to the village center, be politically active in the village, and benefit from other social protection programs. In summary, Table 4 paints a picture in which the final beneficiary selection is 
progressive (with respect to poverty) - an effect that is composed of a progressive eligibility rule imposed by the center and a neutral process of applications and selection among the eligible within villages.

In Table 4, we decomposed final beneficiary status at the household level into eligibility and, conditional on eligibility, the within-village selection process. However, we can also decompose the within-village selection process among eligible households - in the spirit of the analysis of applications and funding at the national level in Section 5. There are no applications from households within villages, but we have data on whether the household was aware of TASAF II, which can be considered as a prerequisite for being able to become a VG beneficiary. $^{39}$ Interestingly, our data show that, among all eligible households in the study villages, just over half of survey respondents had ever heard of the program. Ineligible households were actually three percentage points more likely to have heard of the program than eligible ones. These numbers prevail despite the fact that the listing survey was conducted after VG groups had been formed and were ready to be funded in each of these 100 villages.

Given the potentially regressive role of information in TASAF II, Table 5 presents a decomposition of the within-village selection process among eligible households into (i) awareness of TASAF II and (ii) likelihood of selection conditional on being aware. While imperfect, the first part of this decomposition is akin to examining the demands of CDD projects from its potential beneficiaries, while the second part sheds light on the decentralized selection of final program beneficiaries within villages. As the sample of eligible households is small, we utilize data on all eligible households in the 100 study villages from the listing survey, which provides us with more statistical power. While all the covariates used in Table 4 are available in the listing survey, we lose the poverty indicator the underlying data used to create our consumption aggregate were not collected in this sample. Therefore, in Table 5, we replace the poverty indicator with a composite consumption indicator that is equal to the total number of days over the past week that the respondent's household had consumed meat, eggs, and milk.

\footnotetext{
39 It should be noted that the parallels between this analysis of 'program awareness' at the household level and 'applications' from villages at the national level are inexact for two additional reasons. First, while they are rare, there are cases where a household is unaware of TASAF while a member is listed as a beneficiary of a VG project. Second, applications at the national level are for all types of programs, many of which seek funding for the creation of public goods (such as schools, clinics, roads, etc.), while VG projects provide private benefits at the household level.
} 
Columns (1) and (2) in Table 5 replicate the same specification in columns (5) and (6) in Table 4 and describe the correlates of being a beneficiary household among eligible households. Beneficiary status is negatively correlated with the consumption of meat, eggs, and milk during the week before the listing survey, indicating that beneficiary selection from the group of eligible households was more progressive with respect to recent consumption of proteins than it was with respect to per capita household consumption. ${ }^{40}$ The next four columns decompose this process into 'awareness' and 'selection' conditional on awareness. Column (3) shows that program awareness significantly increases with household food consumption among eligible households, suggesting, as in the analysis of applications at the national level, a regressive demand-driven process. Column (4) shows that program awareness increases (conditionally) on almost every indicator of advantage examined in this table: education, access to media, political activity, connectedness to village elites, and benefitting from previous social safety net programs. The majority of poorer, vulnerable, and marginalized households were not even aware of this program designed to assist them. Hence, we see a repeat of the regressive pattern at the applications stage that carries all the way through to the final beneficiary pool.

Columns (5) and (6) attempt to recreate the spirit of the national-level results on the probability of funding conditional on application (implicit in Table 2) by examining the correlates of being a VG project beneficiary among eligible households aware of TASAF. This is the group that is potentially capable of attempting to pull demand-driven benefits to themselves, and hence gives a metric of within-village targeting efficiency abstracting away from both eligibility and informational requirements. Within this group, we see that selection is progressive on socio-economic variables such as food consumption and ownership of a radio or a mobile phone. Once again, however, we see that proximity to village center, as well as political activity and connectedness are powerful correlates of receiving benefits. Within this group, all else equal, an individual belonging to a household wherein a member holds village office is 10 pp more likely to be a TASAF II beneficiary, and beneficiaries of previous social protection programs for vulnerable groups are 27 pp more likely to benefit from this new wave of projects. Politically

\footnotetext{
${ }^{40}$ This slight change in findings when we move from column (5) of Table 4 to column (1) of Table 5 seems due to the change in the welfare indicator used as an explanatory variable: if we run the same regression in column (1) of Table (5) restricting the analysis to the household survey sample in column (5) of Table 4, we get very similar results. That the findings in column (6) of Table 4 and column (2) of Table 5 are qualitatively the same for the additional covariates further indicates that the findings are robust to switching from using the household survey sample in Table 4 to using the entire population in Table 5.
} 
connected households are both more likely to have heard about the program and more likely to benefit from it conditional on awareness.

\section{Concluding Discussion and Policy Implications}

In this study, we provide new quantitative evidence on the separate forces underlying the final targeting performance of a major community-driven development program in Tanzania. The bottom-up, beneficiary-driven dimension of the program results in a regressive intake sample of individuals that are aware of and apply for the program, setting the selection process off at a disadvantage relative to the overall population. The requirement that individuals take action to be considered as beneficiaries, then, presents a regressive demand on this demanddriven development program. From this starting point, a variety of forces conspire to push the final beneficiary distribution back to a moderately progressive state. A cross-district funding formula set by the government was intended to be progressive but, using an independent poverty measure, we find it to be poverty-neutral. Interestingly, however, this cross-district formula plays an important and perhaps unanticipated role, effectively neutralizing the substantial and regressive cross-district variation in application rates. The district- and local-level agents to whom decentralized targeting is delegated are effective at targeting, resulting in higher per capita allocations to wards that are significantly poorer than their district averages. However, this selection process does not neutralize the extent to which politically active wards are overrepresented in the applicant pool: per capita TASAF II spending is also higher in wards that are more politically engaged within districts.

Our analysis at the household level strongly mirrors these findings. The centrally stipulated eligibility rule for the Vulnerable Groups program is effective in selecting a poor sample, but that knowledge of the program is highly regressive. In a centrally targeted program the knowledge that potential beneficiaries hold about the program when it begins may be next to irrelevant, but in a demand-driven project it is critical. ${ }^{41} \mathrm{~A}$ household cannot seek inclusion in a

\footnotetext{
${ }^{41}$ There are obviously many cash transfer programs, such as PROGRESA in Mexico, that do not require their beneficiaries to submit applications. A newer wave of cash transfer programs that take advantage of idiosyncratic information (and preferences) at the local level, such as BLT in Indonesia (Alatas et al. 2013) also partially rely on communities to determine beneficiaries but do not require them to apply. On the other hand, Oportunidades - an expansion of PROGRESA into urban areas - did use applications as a self-selection mechanism before applying a proxy-means test to select beneficiaries from the pool of applicants.
} 
demand-driven program of which it has not heard. We find that barely half of the eligible households had ever heard of TASAF at baseline. Similar to the pattern for project applications at the ward level, we find that households who are more educated, have better access to media and information, active in village affairs, and related to village elites are substantially more likely to have heard of TASAF. Again, the decentralized actors are successful at selecting a final beneficiary pool relative to the universe from which they are allowed to choose: the eligible and informed. Eligible households that are related to village elites and attend village meetings are more likely to have heard of the program and more likely to benefit conditional on awareness.

The main contribution of this paper is to document the precise ways in which the demand-driven nature of community development programs may be hindering their ability to reach the poor. The lack of applications from poor households and communities could be due to various factors, among which lack of information, suggested here, is only one. For example, it is possible that poor households (or communities) are aware of the program but unable to navigate the system to produce valid applications. The evidence we have at the household level suggests that this may be part of the story: group leaders for the proposed income generating activities are substantially more educated, more likely to own phones and radios, and less likely to be poor than the "rank and file" members of these groups. ${ }^{42}$ It is likely that these individuals are instrumental in putting together viable project proposals and navigating the application process. ${ }^{43}$

Another possibility is that households and communities that are aware of TASAF (and able to apply) nonetheless decide against doing so. Low application rates among the poor might arise if they rationally decide not to apply due to a perceived low probability of being approved. The data available to us also argue against this idea. Approval rates are higher in poorer wards, meaning that, if anything, application rates from these areas should be higher. Hence we conclude that the regressive pool of applications is likely to be arising from variation in access to

\footnotetext{
42 The analysis of VG project leaders is not included in this paper but is available from the authors upon request. While these households are technically eligible under the criteria imposed by the center, their average consumption level is closer to ineligible households than eligible ones.

${ }^{43}$ It is important to recognize that the Vulnerable Groups component of TASAF II is not a palliative poverty reduction program, but rather aims to reduce poverty by making grants to groups of vulnerable individuals, who are supposed to invest the funds into a proposed income generating activity, and thereby creating a sustainable stream of income. If the successful creation of such small enterprises is much harder when groups consist entirely of uneducated, inexperienced, and marginalized individuals, then the inclusion of better educated, well-connected, and richer individuals - i.e. the very definition of group leaders described above - may make sense. Considered in this light, what may look like 'capture' or 'mistargeting' may actually be the key to the longer-term success of these income-generating activities. An ongoing randomized impact evaluation of these subprojects will permit us to analyze this issue in great detail in the near future.
} 
information (and perhaps in the ability to produce viable applications), connections to local officials, and civic engagement, rather than the high costs or low perceived benefits of applying.

The presumably accidental way in which the district funding formula neutralized the cross-district variation in applications suggests a way of thinking about how to make targeting neutral to distortions. The regressive heterogeneity in application rates is like a 'squeaky wheel,' whereby well-informed and politically active individuals are trying to appropriate social funds spending. When a distortion such as this is primarily found across political sub-units, the simple act of 'decentralizing' spending by distributing fixed amounts to each sub-unit will neutralize it. This suggests that we can use survey data to estimate the intra-cluster correlations of such factors and target those clusters directly when they are high. ${ }^{44}$ This relationship represents an interesting way in which pure statistics can guide policymaking. ${ }^{45}$

Our study confirms findings in the literature with respect to the advantages enjoyed by local elites in decentralized programs, while suggesting a new culprit for this pattern. Despite the fact that community development projects are supposed to be designed to address the needs of the "poor, the marginalized, and the excluded", we find that these are exactly the groups among whom the awareness of the program is lowest. The importance of civic engagement and political connections permeates our results. Unlike measures of poverty, variables measuring political activity and connectedness increase both the demand-side probability to seek out the program as well as the supply-side probability of selection. The final distribution of program benefits thus ends up skewed heavily towards districts and wards with high voter registration and turnout, and towards households that have direct connections to village political elites. While our data do not allow us to distinguish active 'informational capture' by elites from the fact that marginalized

\footnotetext{
${ }^{44}$ Baker and Grosh (1994) and Elbers et al. (2007) both find that targeting smaller administrative units, by using "poverty maps" or similar data, would produce large gains in poverty reduction.

${ }^{45}$ Another dimension in which the statistical exercise conducted in this study may be relevant to researchers, especially downstream users of poverty maps, is in the correction of standard errors for predicted explanatory variables. While several authors have pointed out that a correction is required (see, for example, Elbers et al. 2005), such corrections are not common in studies making use of poverty maps in downstream research. One take-away from the bootstrapping exercise in this study is that the effect of this error is modest, and, as expected, decreases with the scale of aggregation. By conducting the bootstrapping exercise with and without the variation across the poverty map simulations, we find that the incorporation of the prediction error from the poverty map causes the standard error of second-stage parameter estimates to increase by $29.6 \%$ in our ward-level analysis (average population 13,370), but by only $11.8 \%$ in the district-level analysis (average population 276,000). While policymakers are rightly worried about using noisy estimates for small administrative units to make important decisions, such as allocating funds across wards, such estimates can be used for research while fully accounting for the error inherent in them.
} 
groups are simply harder to sensitize, the informational disadvantage among the poor that pervades this study motivates a strong focus on outreach efforts in CDD programs. ${ }^{46}$

A variety of community-driven development programs require their potential beneficiaries to be aware of and fully participate in the entire process, but the ability to do so is not equitably distributed across the population. Rather, it is significantly lower among the poor, the vulnerable, and the marginalized. Inducing meaningful participation at the local levels remains a big hurdle for these programs to truly succeed.

\footnotetext{
${ }^{46}$ For example, the amount of funds devoted to "information, education, and communication" were approximately $1 \%$ of the NVF funds. Even a small increase in the availability of such funds for better sensitization and outreach could make a difference in the application pool and in the knowledge applicants have of their rights.
} 


\section{References}

Alatas, V., Banerjee, A., Hanna, R., Olken, B.A., Purnamasari, R., and Wai-Poi, M., 2013. “Does Elite Capture Matter? Local Elites and Targeted Welfare Programs in Indonesia,” unpublished manuscript.

Alatas, V., Banerjee, A., Hanna, R., Olken, B.A., and Tobias, J., 2012. "Targeting the Poor: Evidence from a Field Experiment in Indonesia,” American Economic Review, 102(4): 12061240.

Alderman, H., 2002. “Do local officials know something we don’t? Decentralization of targeted transfers in Albania,” Journal of Public Economics, 82: 375-404.

Araujo, M. C., Ferreira, F.H.G., Lanjouw, P., and Özler, B., 2008. "Local inequality and project choice: Theory and evidence from Ecuador," Journal of Public Economics, 92(5-6): 1022-1046.

Arcand, J.-L., Bassole, L., and Tranchant, J.-P., 2006. "The Making of a (vice-) President: Party Politics, Ethnicity, Village Loyalty and Community-Driven Development," Working Papers 2006.33, CERDI.

Baker, J., and Grosh, M., 1994. "Poverty Reduction Through Geographic Targeting: How Well Does it Work?” World Development, 22(7): 983-995.

Bardhan, P., and Mookherjee, D., 2000. "Capture and governance at local and national levels,” American Economic Review, 90(2): 135-139.

Bardhan, P., and Mookherjee, D., 2005. "Decentralizing antipoverty program delivery in developing countries,” Journal of Public Economics, 89: 675-704.

Besley, T. Pande, R., and Rao, V., 2007. "Just Rewards? Local Politics and Public Resource Allocation in South India," STICERD - Development Economics Papers.

Borjas, G., 1980. "The Relationship between Wages and Weekly Hours of Work: The Role of Division Bias,” The Journal of Human Resources 15(3): 409-423.

Camacho, A., and Conover, E., 2011. "Manipulation of Social Program Eligibility," American Economic Journal: Economic Policy, 3(2): 41-65.

Coady, D. P., and Parker, S. W., 2009. "Targeting Performance under Self-selection and Administrative Targeting Methods,” Economic Development and Cultural Change 57(3): 559587.

Conning, J., and Kevane, M., 2002. "Community-based targeting mechanisms for social safety nets: a critical review,” World Development 30(3): 375-394.

Cox, G., and McCubbins, M., 1986. "Electoral Politics as a Redistributive Game,” The Journal of Politics, 48(2): 370-389. 
Dasgupta, A., and Beard, V.A., 2007. "Community-Driven Development, Collective Action, and Elite Capture in Indonesia,” Development and Change, 38:229-249.

Dixit, A., and Londregan, J., 1996. "The Determinants of Success of Special Interests in Redistributive Politics,” The Journal of Politics, 58(4): 1132-1155.

Dutta, Puja, Rinku Murgai, Martin Ravallion and Dominique van de Walle, 2012, Rozgar Guarantee? Assessing India's Biggest Anti-Poverty Program in India's Poorest State, World Bank, Washington DC, forthcoming.

Elbers, C., Lanjouw, J.O., and Lanjouw, P., 2003. "Micro-Level Estimation of Poverty and Inequality." Econometrica 71(1): 355-364.

Elbers, C., Lanjouw, J., and Lanjouw, P., 2005. "Imputed Welfare Estimates in Regression Analysis,” Journal of Economic Geography, 5(1): 101-118.

Elbers, C., Fujii, T., Lanjouw, P., Özler, B., and Yin, W., 2007. "Poverty Alleviation Through Geographic Targeting: How Much Does Disaggregation Help?” Journal of Development Economics, 83(1): 198-213.

Francken, N., Minten, B., and Swinnen, J.F.M., 2009. "Media, Monitoring, and Capture of Public Funds: Evidence from Madagascar," World Development, 37(1): 242-255.

Galasso, E., and Ravallion, M., 2005. “Decentralized targeting of an antipoverty program,” Journal of Public Economics, 89: 705-727.

Khemani, S., 2010. "Political Capture of Decentralization. Vote-Buying through GrantsFinanced Local Jurisdictions,” World Bank Policy Research Working Paper 5350. Washington, D.C.

Kochar, A., Singh, K., and Singh, S., 2009. “Targeting Public Goods to the Poor in a Segregated Economy: An Empirical Analysis of Central Mandates in Rural India,” Journal of Public Economics, 93: 917-930.

Labonne, J. and Chase, R., 2009. "Who is at the Wheel when Communities Drive Development? Evidence from the Philippines,” World Development 37(1): 219-231.

Mansuri, G., and Rao, V., 2012. Localizing Development: Does Participation Work? Policy Research Report, Development Research Group, World Bank, Washington, D.C.

Olken, B.A., 2007. "Monitoring Corruption: Evidence from a Field Experiment in Indonesia," Journal of Political Economy, 115: 200-249.

Paxson, C., and Schady, N., 1999. "Do School Facilities Matter? The Case of the Peruvian Social Fund (FONCODES),” World Bank Policy Research Working Paper 2229. Washington, D.C. 
Paxson, C., and Schady, N., 2002. "The Allocation and Impact of Social Funds: Spending on School Infrastructure in Peru,” The World Bank Economic Review, 16(2): 297-319.

Platteau, J.-P., and Gaspart, F., 2003. “The Risk of Resource Misappropriation in CommunityDriven Development,” World Development, 31(10): 1687-1703.

Rao, V., and Ibanez, A.M., 2003. "The Social Impact of Social Funds in Jamaica: A 'Participatory Econometric' Analysis of Targeting, Collective Action, and Participation in Community-Driven Development,” Journal of Development Studies, 41: 788-838.

Ravallion, M., 2000. "Monitoring Targeting Performance When Decentralized Allocations to the Poor Are Unobserved,” World Bank Economic Review, 14(2): 331-345.

Ravallion, M., 2009. "How Relevant is Targeting to the Success of an Antipoverty Program?” World Bank Research Observer, 24: 205-231.

Reinikka, R., and Svensson, J., 2004. "Local Capture: Evidence From a Central Government Transfer Program in Uganda," The Quarterly Journal of Economics, 119(2): 678-704.

Reinikka, R., and Svensson, J., 2011. "The power of information in public services: Evidence from education in Uganda," Journal of Public Economics, 95(7-8): 956-966.

Schady, N.R., 2000. "The Political Economy of Expenditures by the Peruvian Social Fund (FONCODES), 1991-95,” The American Political Science Review, 94(2): 289-304.

Shankar, S., Gaiha R., and Jha, R., 2011. "Information, Access, and Targeting: The National Rural Employment Guarantee Scheme in India,” Oxford Development Studies, 39(1): 69-95.

World Bank, 2002. "Social Funds: Assessing Effectiveness,” World Bank Operations Evaluation Department, The World Bank, Washington D.C. 


\section{TABLES}

\section{Table 1: Summary Statistics}

\begin{tabular}{|c|c|c|c|c|c|c|c|c|}
\hline \multicolumn{5}{|c|}{ Ward-level analysis: } & \multicolumn{4}{|c|}{ Household/Listing survey analysis: } \\
\hline \multicolumn{2}{|c|}{ Targeting Outcome variables: } & Mean & Std. Dev. & Obs & & Mean & Std. Dev. & Obs \\
\hline & TASAF spending (US \$ per capita) & 3.072 & 3.800 & 2,177 & Household is Eligible (Vulnerable) & 0.213 & 0.409 & 29,882 \\
\hline & Funded projects per 1000 ward residents & 0.096 & 0.156 & 2,177 & Household is Beneficiary, among eligibles & 0.131 & 0.337 & 10,894 \\
\hline & Project applications per 1000 ward residents & 3.057 & 5.436 & 2,177 & Heard of TASAF, among eligibles & 0.543 & 0.498 & 10,894 \\
\hline & Percentage of applications funded & 12.917 & 25.012 & 2,111 & & & & \\
\hline \multirow[t]{3}{*}{ Poverty/Inequality: } & Poverty Headcount Ratio & 0.340 & 0.184 & 2,177 & Household is poor (Household survey sample only) & 0.597 & 0.491 & 1,297 \\
\hline & Population, 000 & 13.370 & 10.400 & 2,177 & Cumulative Days milk, meat, eggs eaten in past week & 2.932 & 3.838 & 29,882 \\
\hline & Area (000 sq km) & 0.027 & 0.051 & 2,177 & & & & \\
\hline \multirow[t]{3}{*}{ Information } & Fraction Urban & 0.221 & 0.373 & 2,177 & Inverse Distance to Village Population Center & 0.032 & 0.077 & 29,882 \\
\hline & Fraction Illiterate & 0.364 & 0.172 & 2,177 & Household Head has Primary Education & 0.497 & 0.500 & 29,882 \\
\hline & Fraction with Radio or Phone & 0.561 & 0.179 & 2,177 & Household owns a Radio or Phone & 0.676 & 0.468 & 29,882 \\
\hline \multirow[t]{3}{*}{ Political Connectedness } & CCM vote share in Presidential Election & 0.807 & 0.097 & 2,177 & Any household member holds village office & 0.053 & 0.224 & 29,882 \\
\hline & & & & & Any $\mathrm{HH}$ member related to village elites & 0.067 & 0.250 & 29,882 \\
\hline & & & & & Any HH member belongs to other VG group & 0.022 & 0.146 & 29,882 \\
\hline Political Activity & Ward Voter Turnout (votes/population) & 0.325 & 0.070 & 2,177 & Attended village meeting past 3 months & 0.465 & 0.499 & 29,882 \\
\hline
\end{tabular}


Table 2

TASAF Applications Received per 1000 People in Ward:

\begin{tabular}{lcccccc|c|c} 
& $\begin{array}{c}\text { Within } \\
\text { Districts }\end{array}$ & $\begin{array}{c}\text { Between } \\
\text { Districts }\end{array}$ & $\begin{array}{c}\text { Total Effect } \\
\text { at Ward } \\
\text { Level }\end{array}$ & $\begin{array}{c}\text { Within } \\
\text { Districts }\end{array}$ & $\begin{array}{r}\text { Between } \\
\text { Districts }\end{array}$ & $\begin{array}{c}\text { Total Effect } \\
\text { at Ward } \\
\text { Level }\end{array}$ \\
\cline { 2 - 8 } & \multicolumn{2}{c}{$(1)$} & $(2)$ & $(3)$ & $(4)$ & $(5)$ & $(6)$ \\
\hline Poverty Headcount Ratio (P0) & 0.66 & $-10.22^{* * *}$ & $-4.60^{* * *}$ & $1.30^{* * *}$ & 0.88 & $1.33^{* * *}$ \\
& $(0.61)$ & $(2.52)$ & $(0.61)$ & $(0.45)$ & $(1.72)$ & $(0.44)$ \\
\hline \hline & & & & & & \\
Observations & 2177 & 119 & 2177 & 2177 & 119 & 2177 \\
R-Squared & 0.375 & 0.146 & 0.024 & 0.389 & 0.002 & 0.004 \\
District-Level Fixed Effects: & $\mathrm{Y}$ & $\mathrm{N}$ & $\mathrm{N}$ & $\mathrm{Y}$ & $\mathrm{N}$ & $\mathrm{N}$
\end{tabular}

*** $\mathrm{p}<0.01,{ }^{* *} \mathrm{p}<0.05,{ }^{*} \mathrm{p}<0.1$. Ward-level analysis weighted by ward population, between regression run at the district level and weighted by district population to be representative of mainland Tanzania. Standard errors calculated by a bootstrapping exercise in which we drew estimates of the poverty headcount from the sub-estimations of the poverty map for each unit, sampled from our data with replacement, and calculated marginal effects 500 times. These standard errors reflect the fact that the core RHS variable is estimated. 
Table 3

Within-District Analysis

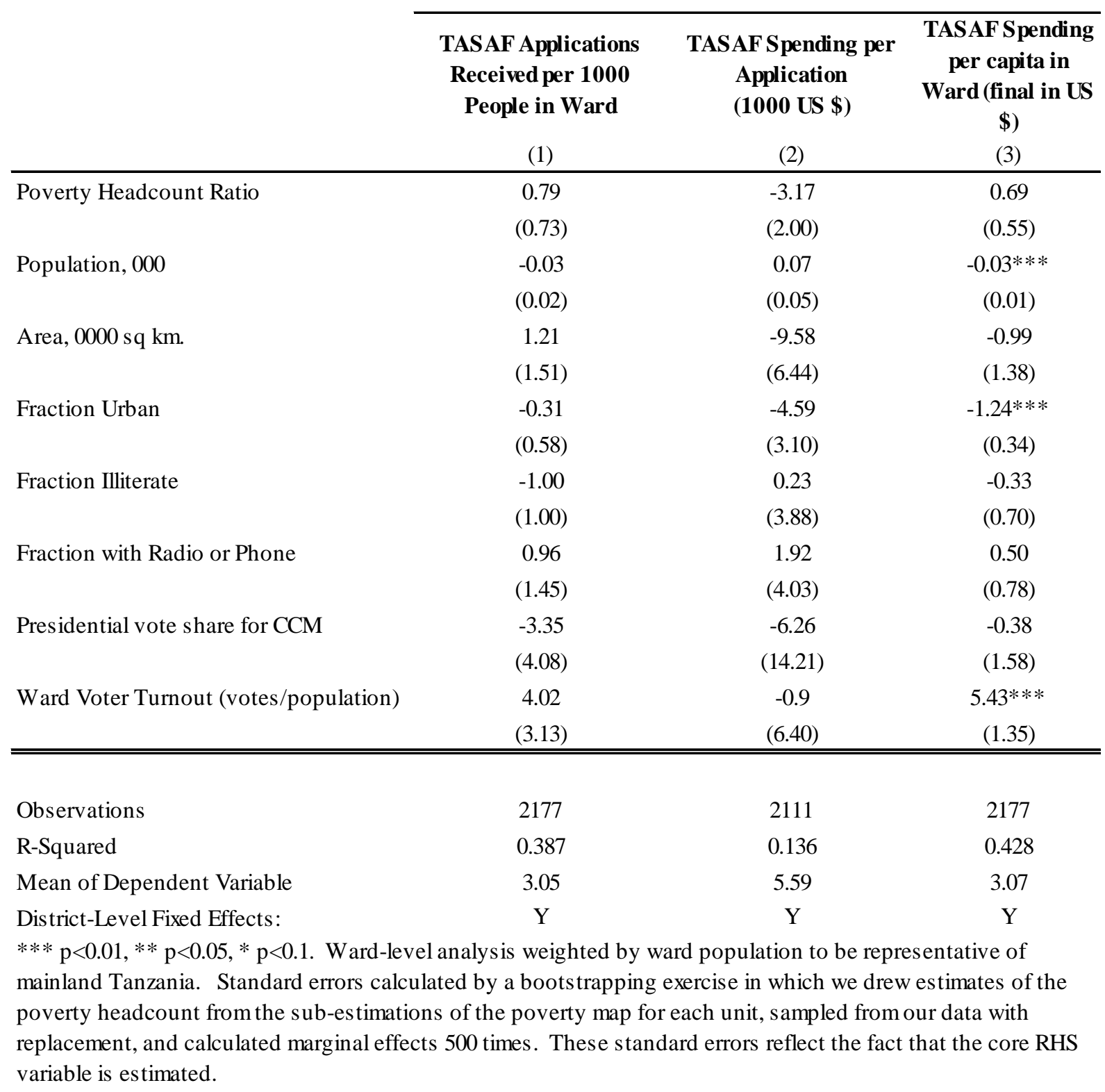




\section{Table 4}

Household-level Targeting of TAS AF VG Membership.

\begin{tabular}{|c|c|c|c|c|c|c|}
\hline & \multicolumn{2}{|c|}{$\begin{array}{c}\text { TASAF beneficiary } \\
\text { (estimated among all } \\
\text { households) }\end{array}$} & \multicolumn{2}{|c|}{$\begin{array}{c}\text { Eligible } \\
\text { (estimated among all } \\
\text { households) }\end{array}$} & \multicolumn{2}{|c|}{$\begin{array}{l}\text { TASAF beneficiary } \\
\text { (estimated among } \\
\text { eligible households) }\end{array}$} \\
\hline & (1) & (2) & (3) & (4) & (5) & (6) \\
\hline \multirow[t]{2}{*}{ Household is poor } & $0.0139 * *$ & 0.0101 & $0.0927 * *$ & 0.0708 & 0.0083 & 0.0114 \\
\hline & $(0.007)$ & $(0.008)$ & $(0.046)$ & $(0.051)$ & $(0.031)$ & $(0.033)$ \\
\hline \multirow[t]{2}{*}{ Inverse Distance to Village Population Center } & & $0.298 * * *$ & & 0.245 & & $0.325^{*}$ \\
\hline & & $(0.076)$ & & $(0.294)$ & & $(0.186)$ \\
\hline \multirow[t]{2}{*}{ Household Head has at least Primary Education } & & $-0.0211 * * *$ & & $-0.285 * * *$ & & $0.0687^{*}$ \\
\hline & & $(0.008)$ & & $(0.042)$ & & $(0.035)$ \\
\hline \multirow[t]{2}{*}{ Household owns a Radio or Phone } & & -0.00742 & & $-0.110 * *$ & & 0.0193 \\
\hline & & $(0.007)$ & & $(0.048)$ & & $(0.032)$ \\
\hline \multirow[t]{2}{*}{ Attended village meeting past 3 months } & & $0.0261 * * *$ & & 0.0513 & & $0.105^{* * *}$ \\
\hline & & $(0.007)$ & & $(0.056)$ & & $(0.031)$ \\
\hline \multirow[t]{2}{*}{ Any household member holds village office } & & $0.0330^{*}$ & & $-0.105^{*}$ & & $0.268^{* *}$ \\
\hline & & $(0.017)$ & & $(0.060)$ & & $(0.118)$ \\
\hline \multirow[t]{2}{*}{ Any HH member related to village elites } & & 0.0231 & & 0.063 & & 0.0699 \\
\hline & & $(0.015)$ & & $(0.066)$ & & $(0.060)$ \\
\hline \multirow[t]{2}{*}{ Any HH member belongs to other VG group } & & $0.134^{* * *}$ & & $0.342 * * *$ & & $0.163^{*}$ \\
\hline & & $(0.044)$ & & $(0.114)$ & & $(0.090)$ \\
\hline Observations & 1297 & 1297 & 1297 & 1297 & 863 & 863 \\
\hline R-Squared & 0.051 & 0.078 & 0.13 & 0.248 & 0.135 & 0.199 \\
\hline Mean of Dep. Var in Sample for Regression: & \multicolumn{2}{|c|}{0.028} & \multicolumn{2}{|c|}{0.214} & \multicolumn{2}{|c|}{0.130} \\
\hline
\end{tabular}

${ }^{* * *} \mathrm{p}<0.01,{ }^{* *} \mathrm{p}<0.05,{ }^{*} \mathrm{p}<0.1$. Regressions are linear probability models with village-level fixed effects and standard errors clustered at the village level. All analyses weighted by household-level sampling weights to make them representative of the 100 study villages. 


\section{Table 5}

\section{Awareness of TAS AF: (estimated among all eligible households)}

\begin{tabular}{|c|c|c|c|c|c|c|}
\hline \multirow[t]{2}{*}{ Dependent Variable: Ever Heard of TASAF. } & \multicolumn{2}{|c|}{$\begin{array}{c}\text { TASAF beneficiary } \\
\text { (estimated among eligible } \\
\text { households) }\end{array}$} & \multicolumn{2}{|c|}{$\begin{array}{c}\text { Aware of TASAF } \\
\text { (estimated among eligible } \\
\text { households) }\end{array}$} & \multicolumn{2}{|c|}{$\begin{array}{c}\text { TASAF beneficiary } \\
\text { (estimated among eligible } \\
\text { households aware of TASAF) }\end{array}$} \\
\hline & $(1)$ & $(2)$ & (3) & $(4)$ & (5) & (6) \\
\hline Cumulative Days milk, meat, eggs eaten in past week & $\begin{array}{c}-0.00599 * * * \\
(0.001)\end{array}$ & $\begin{array}{c}-0.00706^{* * *} \\
(0.001)\end{array}$ & $\begin{array}{c}0.00958 * * * \\
(0.002)\end{array}$ & $\begin{array}{l}0.00247 \\
(0.002)\end{array}$ & $\begin{array}{c}-0.0124 * * * \\
(0.001)\end{array}$ & $\begin{array}{c}-0.0115^{* * *} \\
(0.001)\end{array}$ \\
\hline Inverse Distance to Village Population Center & & $\begin{array}{l}0.0331 \\
(0.037)\end{array}$ & & $\begin{array}{l}-0.0194 \\
(0.044)\end{array}$ & & $\begin{array}{l}0.178 * \\
(0.091)\end{array}$ \\
\hline Household Head has at least Primary Education & & $\begin{array}{c}0.0414^{* * *} \\
(0.009)\end{array}$ & & $\begin{array}{c}0.181^{* * * *} \\
(0.013)\end{array}$ & & $\begin{array}{l}0.0149 \\
(0.014)\end{array}$ \\
\hline Household owns a Radio or Phone & & $\begin{array}{c}0.000112 \\
(0.008)\end{array}$ & & $\begin{array}{c}0.115^{* * *} \\
(0.012)\end{array}$ & & $\begin{array}{c}-0.0406 * * * \\
(0.014)\end{array}$ \\
\hline Attended village meeting past 3 months & & $\begin{array}{c}0.0666^{* * *} \\
(0.011)\end{array}$ & & $\begin{array}{c}0.138 * * * \\
(0.012)\end{array}$ & & $\begin{array}{c}0.0693 * * * \\
(0.016)\end{array}$ \\
\hline Any household member holds village office & & $\begin{array}{c}0.126 * * * \\
(0.024)\end{array}$ & & $\begin{array}{c}0.197 * * * \\
(0.027)\end{array}$ & & $\begin{array}{c}0.0984 * * * \\
(0.028)\end{array}$ \\
\hline Any HH member related to village elites & & $\begin{array}{l}0.0127 \\
(0.014)\end{array}$ & & $\begin{array}{c}0.0502 * * * \\
(0.018)\end{array}$ & & $\begin{array}{l}0.0018 \\
(0.019)\end{array}$ \\
\hline Any HH member belongs to other VG group & & $\begin{array}{c}0.228 * * * \\
(0.035) \\
\end{array}$ & & $\begin{array}{c}0.111^{* * * *} \\
(0.024) \\
\end{array}$ & & $\begin{array}{c}0.269 * * * \\
(0.037) \\
\end{array}$ \\
\hline Observations & 10,894 & 10,894 & 10,894 & 10,894 & 5916 & 5916 \\
\hline R-squared & 0.134 & 0.173 & 0.11 & 0.194 & 0.154 & 0.188 \\
\hline Mean of Dep. Var in Sample for Regression: & & & & & & \\
\hline
\end{tabular}




\section{FIGURES}

Figure 1: 'Waterfall' of TASAF Application and Disbursal.

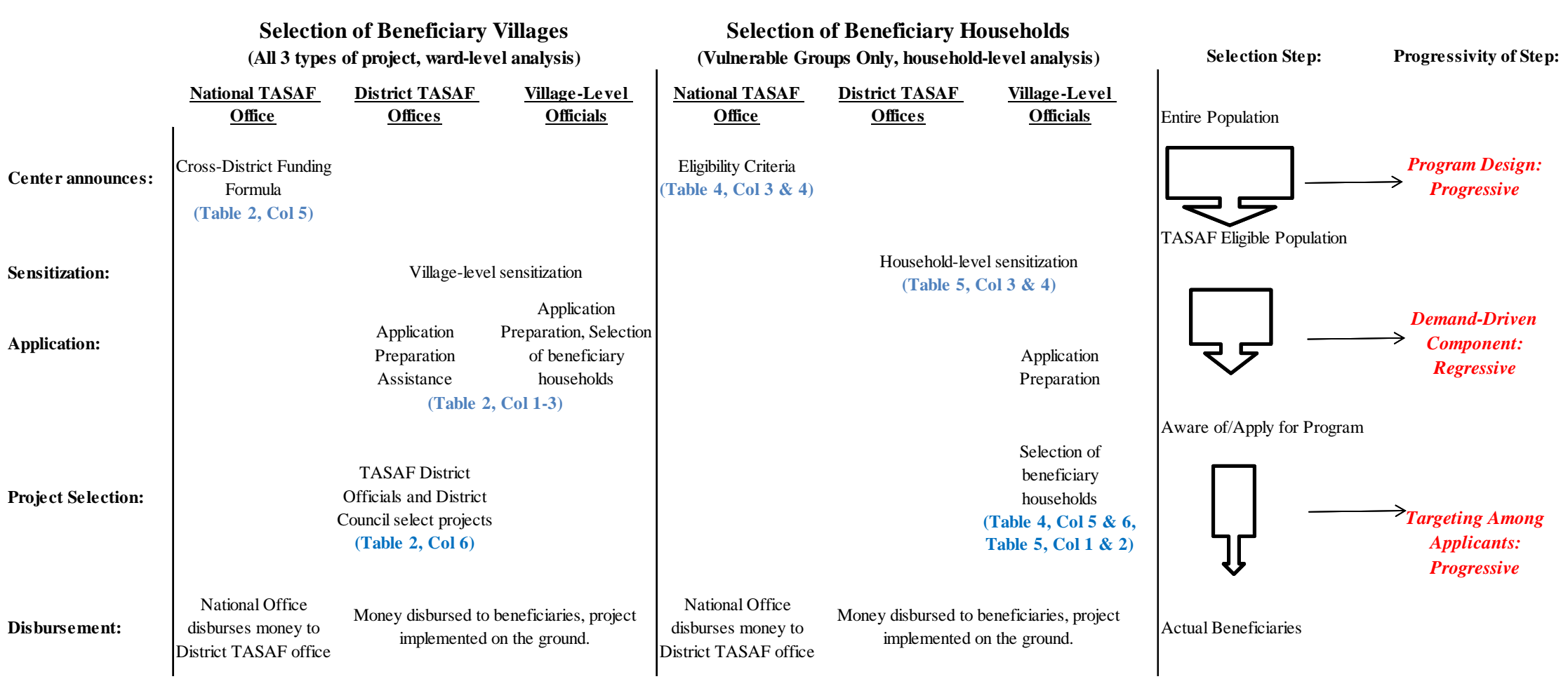


Figure 2a. Applications \& Acceptance Rates, by Poverty Headcount

\section{Application \& Acceptance Rates, by Poverty Headcount}

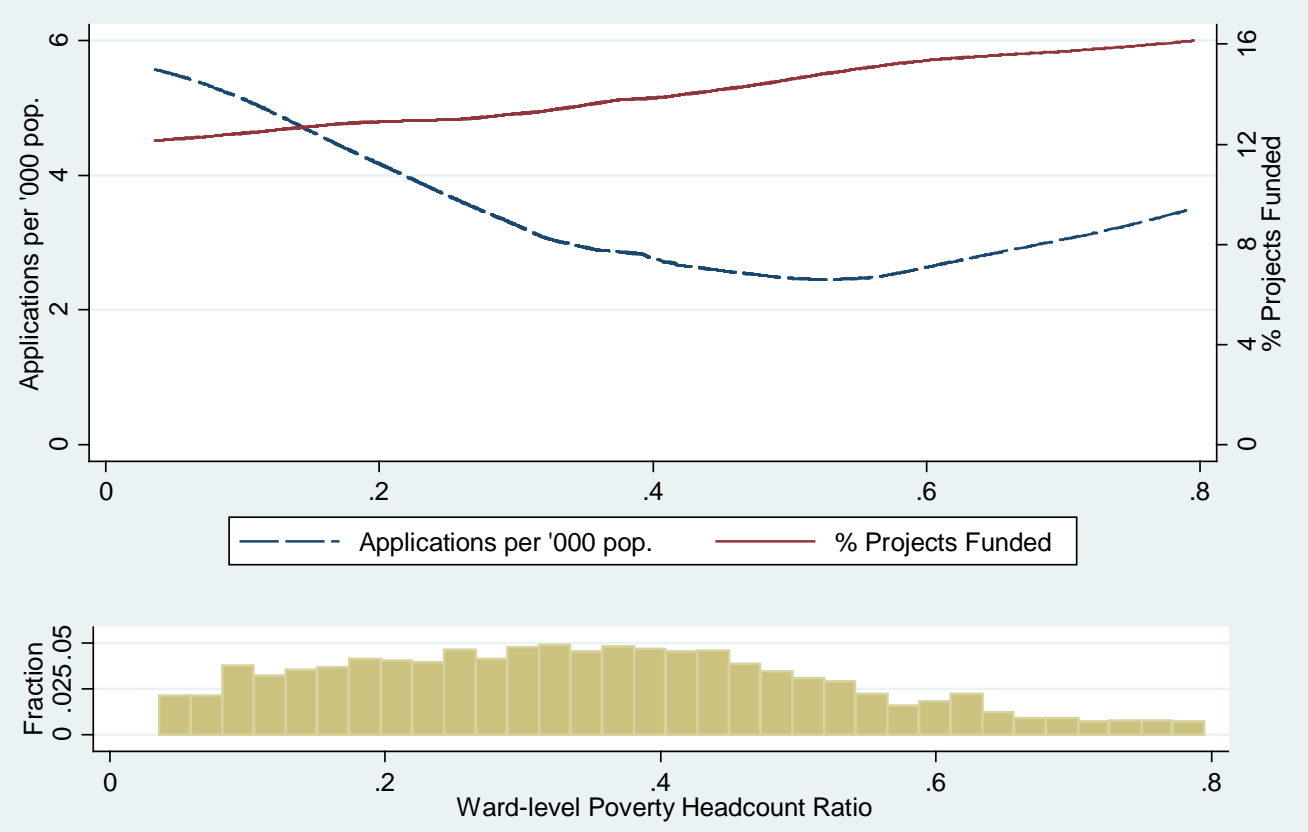

Histogram of Poverty Headcounts given in bottom panel, $5 \%$ tails of poverty distribution trimmed 
Figure 2b. Spending per Capita, by Poverty Headcount

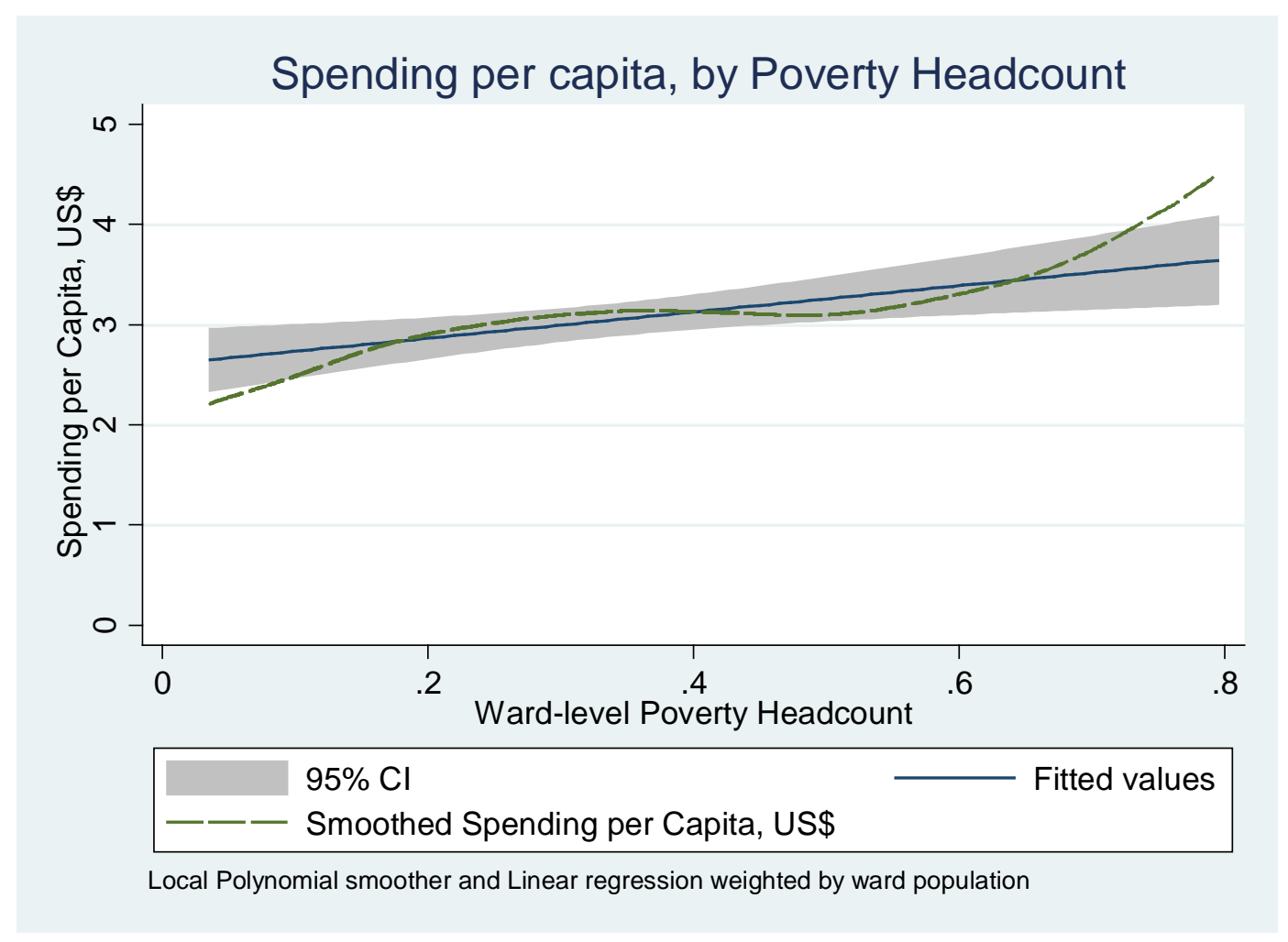




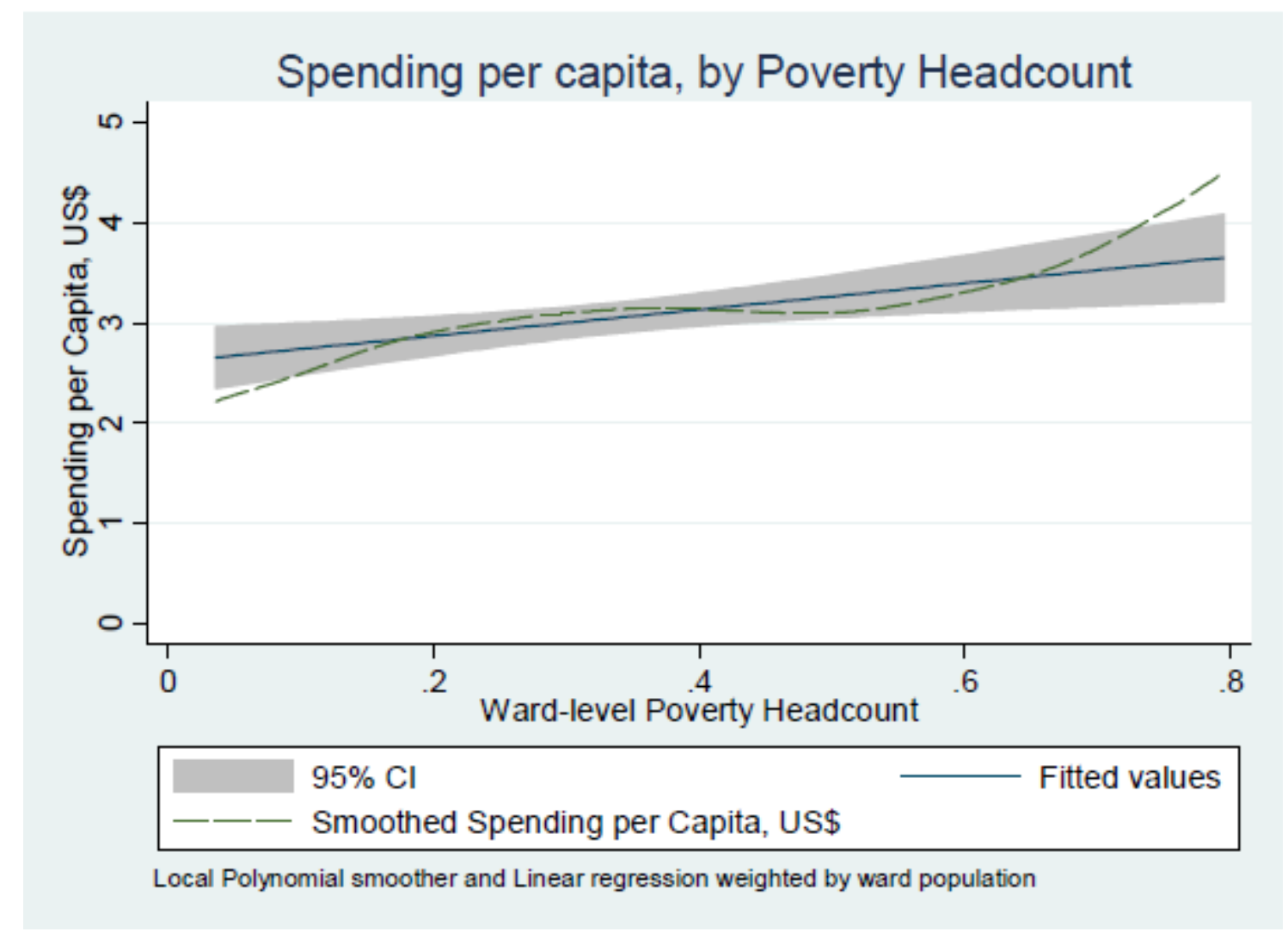


Figure 3: Consumption CDFs by Group, Household Data.

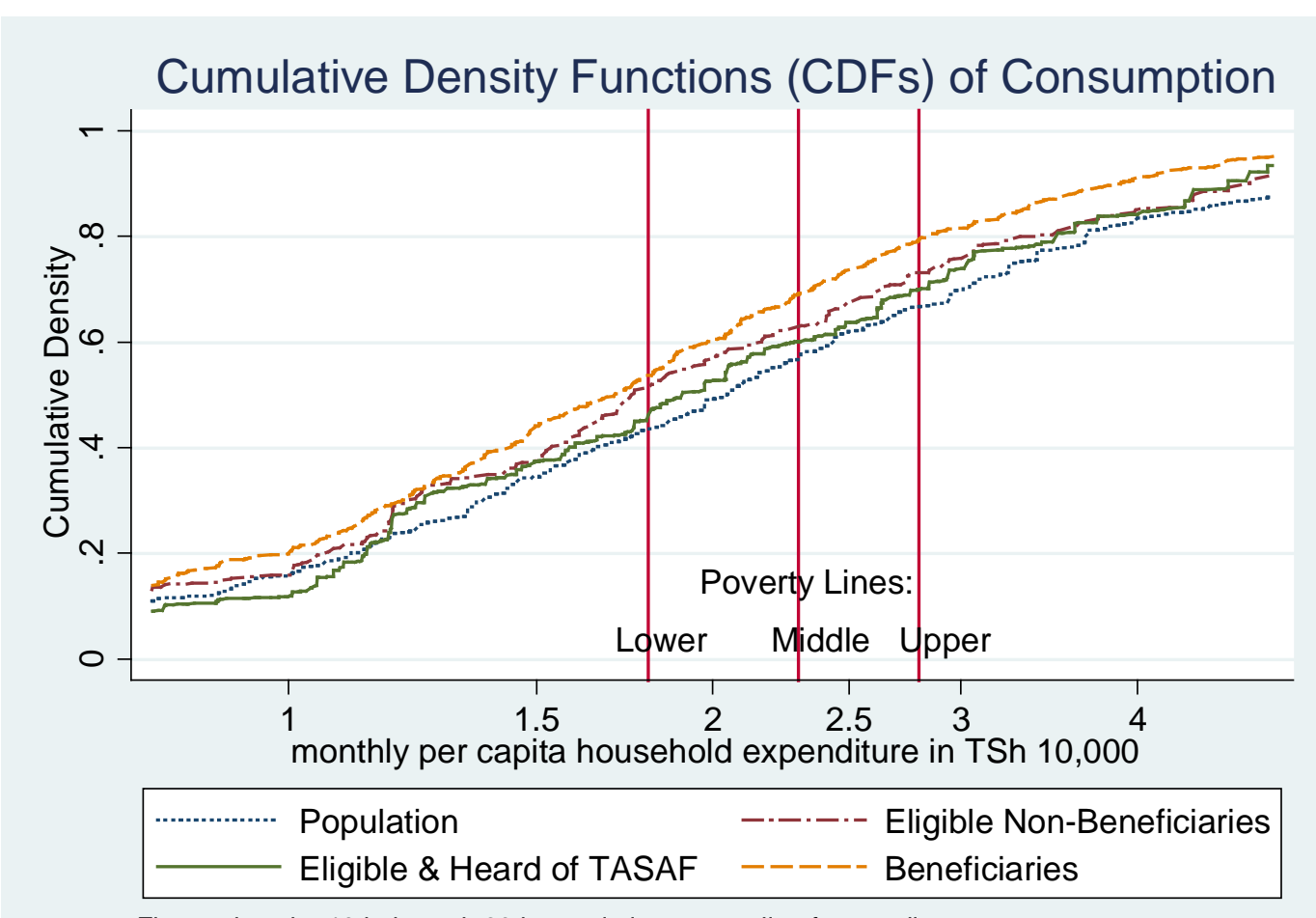

Figure plots the 10th through 90th population percentile of expenditure 
Between-District Analysis

TASAF Applications

\begin{tabular}{|c|c|c|c|c|c|c|}
\hline & $\begin{array}{l}\text { Applications } \\
\text { Received (per } \\
\text { 1,000 people) }\end{array}$ & $\begin{array}{l}\text { Percentage of } \\
\text { Applications } \\
\text { Funded }\end{array}$ & $\begin{array}{l}\text { Applications } \\
\text { Received (per } \\
\text { 1,000 people) }\end{array}$ & $\begin{array}{c}\text { Budgeted } \\
\text { TASAF } \\
\text { Spending per } \\
\text { capita (US \$) }\end{array}$ & $\begin{array}{c}\text { Budgeted } \\
\text { TASAF } \\
\text { Spending per } \\
\text { capita (US \$) }\end{array}$ & $\begin{array}{c}\text { Actual } \\
\text { TASAF } \\
\text { Spending per } \\
\text { capita (US \$) }\end{array}$ \\
\hline & $(1)$ & $(2)$ & (3) & (4) & (5) & (6) \\
\hline Poverty Headcount Ratio & $\begin{array}{c}-10.22^{* * *} \\
(2.52)\end{array}$ & $\begin{array}{c}17.59 * * * \\
(6.68)\end{array}$ & $\begin{array}{l}-4.04 \\
(2.98)\end{array}$ & $\begin{array}{l}-0.12 \\
(1.59)\end{array}$ & $\begin{array}{c}0.04 \\
(1.18)\end{array}$ & $\begin{array}{c}1.09 \\
(1.50)\end{array}$ \\
\hline Population, 000 & & & $\begin{array}{c}0.000 \\
(0.002)\end{array}$ & & $\begin{array}{c}-0.01^{* * *} \\
(0.002)\end{array}$ & $\begin{array}{c}-0.00 * * * \\
(0.002)\end{array}$ \\
\hline Area, $0000 \mathrm{sq} \mathrm{km}$. & & & $\begin{array}{l}-0.36 \\
(0.36)\end{array}$ & & $\begin{array}{c}0.97 * * * \\
(0.33)\end{array}$ & $\begin{array}{l}0.88^{*} \\
(0.46)\end{array}$ \\
\hline Fraction Urban & & & $\begin{array}{c}1.85 \\
(2.57)\end{array}$ & & $\begin{array}{l}1.26^{*} \\
(0.69)\end{array}$ & $\begin{array}{l}1.46^{*} \\
(0.88)\end{array}$ \\
\hline Fraction Illiterate & & & $\begin{array}{c}3.67 \\
(4.28)\end{array}$ & & $\begin{array}{c}0.04 \\
(1.27)\end{array}$ & $\begin{array}{c}0.93 \\
(1.66)\end{array}$ \\
\hline Fraction with Radio or Phone & & & $\begin{array}{c}8.55^{* *} \\
(4.04)\end{array}$ & & $\begin{array}{c}1.19 \\
(1.15)\end{array}$ & $\begin{array}{l}-1.43 \\
(1.60)\end{array}$ \\
\hline Presidential vote share for CCM & & & $\begin{array}{c}0.73 \\
(4.37)\end{array}$ & & $\begin{array}{l}-0.29 \\
(1.39)\end{array}$ & $\begin{array}{l}-2.24 \\
(2.09)\end{array}$ \\
\hline Ward Voter Turnout (votes/population) & & & $\begin{array}{c}16.59 * * \\
(6.37) \\
\end{array}$ & & $\begin{array}{l}7.25^{*} \\
(3.81) \\
\end{array}$ & $\begin{array}{c}19.16^{* * *} \\
(4.98) \\
\end{array}$ \\
\hline Observations & 119 & 119 & 119 & 119 & 119 & 119 \\
\hline R-Squared & 0.146 & 0.038 & 0.343 & 0.0000 & 0.455 & 0.412 \\
\hline Mean of Dependent Variable & 3.02 & 8.05 & 3.02 & 3.58 & 3.58 & 3.15 \\
\hline
\end{tabular}

TASAF Spending per capita (US \$)

\section{TASAF Spending per capita (US \$)}

Budgeted Budgeted Actual

Applications Percentage of Applications TASAF TASAF TASAF

Received (per Applications Received (per Spending per Spending per Spending per 


\section{APPENDIX TABLE ॥}

Panel A: Alternate measure of Poverty: TASAF Applications Received
per 1000 People in Ward:
TASAF Spending per Person in Ward(US \$):

\begin{tabular}{|c|c|c|c|c|c|c|}
\hline & Within Districts & $\begin{array}{l}\text { Between } \\
\text { Districts }\end{array}$ & $\begin{array}{l}\text { Total Effect at } \\
\text { Ward Level }\end{array}$ & Within Districts & $\begin{array}{l}\text { Between } \\
\text { Districts }\end{array}$ & $\begin{array}{c}\text { Total Effect at } \\
\text { Ward Level }\end{array}$ \\
\hline & (1) & (2) & (3) & (4) & (5) & (7) \\
\hline Poverty Gap (P1) & $\begin{array}{c}1.28 \\
(1.21) \\
\end{array}$ & $\begin{array}{c}-22.21 * * * \\
(6.55)\end{array}$ & $\begin{array}{c}-9.03 * * * \\
(1.40)\end{array}$ & $\begin{array}{c}3.02 * * \\
(1.13)\end{array}$ & $\begin{array}{l}-0.66 \\
(4.94) \\
\end{array}$ & $\begin{array}{c}3.42 * * * \\
(1.17)\end{array}$ \\
\hline Observations & 2177 & 119 & 2177 & 2177 & 119 & 2177 \\
\hline R-Squared & 0.375 & 0.111 & 0.017 & 0.389 & 0.0001 & 0.005 \\
\hline District-Level Fixed Effects: & $\mathrm{Y}$ & $\mathrm{N}$ & $\mathrm{N}$ & $\mathrm{Y}$ & $\mathrm{N}$ & $\mathrm{N}$ \\
\hline
\end{tabular}

*** $\mathrm{p}<0.01,{ }^{* *} \mathrm{p}<0.05, * \mathrm{p}<0.1$. Bootstrapped standard errors in parentheses. Ward-level analysis weighted by ward population. Between regression run at the district level and weighted by district population. Standard Errors are bootstrapped.

Panel B: Controlling for 1/Population:

\begin{tabular}{|c|c|c|c|c|c|c|}
\hline & \multicolumn{3}{|c|}{$\begin{array}{l}\text { TASAF Applications Received } \\
\text { per } 1000 \text { People in Ward: }\end{array}$} & \multicolumn{3}{|c|}{$\begin{array}{c}\text { TASAF Spending } \\
\text { per Person in Ward(US \$): }\end{array}$} \\
\hline & Within Districts & $\begin{array}{l}\text { Between } \\
\text { Districts }\end{array}$ & $\begin{array}{c}\text { Total Effect at } \\
\text { Ward Level }\end{array}$ & Within Districts & $\begin{array}{l}\text { Between } \\
\text { Districts }\end{array}$ & $\begin{array}{c}\text { Total Effect at } \\
\text { Ward Level }\end{array}$ \\
\hline & (1) & (2) & (3) & (4) & (5) & (7) \\
\hline Poverty Headcount Ratio (PO) & $\begin{array}{c}0.22 \\
(0.61)\end{array}$ & $\begin{array}{c}-10.20 * * * \\
(2.85)\end{array}$ & $\begin{array}{c}-4.86 * * * \\
(0.59)\end{array}$ & $\begin{array}{c}0.38 \\
(0.34)\end{array}$ & $\begin{array}{c}0.95 \\
(1.01)\end{array}$ & $\begin{array}{c}0.51 \\
(0.43)\end{array}$ \\
\hline 1/Population & $\begin{array}{c}12.99 * * * \\
(2.92) \\
\end{array}$ & $\begin{array}{c}123.1 \\
(118.92) \\
\end{array}$ & $\begin{array}{c}11.04 * * * \\
(2.53) \\
\end{array}$ & $\begin{array}{c}26.91 * * * \\
(1.86) \\
\end{array}$ & $\begin{array}{c}760.76^{* * *} \\
(78.95) \\
\end{array}$ & $\begin{array}{c}35.64 * * * \\
(2.13) \\
\end{array}$ \\
\hline Observations & 2177 & 119 & 2177 & 2177 & 119 & 2177 \\
\hline R-Squared & 0.386 & 0.153 & 0.036 & 0.482 & 0.578 & 0.251 \\
\hline District-Level Fixed Effects: & $\mathrm{Y}$ & $\mathrm{N}$ & $\mathrm{N}$ & $\mathrm{Y}$ & $\mathrm{N}$ & $\mathrm{N}$ \\
\hline
\end{tabular}

*** $\mathrm{p}<0.01,{ }^{* *} \mathrm{p}<0.05,{ }^{*} \mathrm{p}<0.1$. Bootstrapped standard errors in parentheses. Ward-level analysis weighted by ward population.

Between regression run at the district level and weighted by district population. Standard Errors are bootstrapped.

Panel C: Regression in Absolute Numbers:

\begin{tabular}{|c|c|c|c|c|c|c|}
\hline & \multicolumn{3}{|c|}{$\begin{array}{l}\text { TAS AF Applications Received } \\
\text { per } 1000 \text { People in Ward: }\end{array}$} & \multicolumn{3}{|c|}{$\begin{array}{c}\text { TASAF Spending } \\
\text { per Person in Ward(US \$): }\end{array}$} \\
\hline & Within Districts & $\begin{array}{l}\text { Between } \\
\text { Districts }\end{array}$ & $\begin{array}{c}\text { Total Effect at } \\
\text { Ward Level }\end{array}$ & Within Districts & $\begin{array}{l}\text { Between } \\
\text { Districts } \\
\end{array}$ & $\begin{array}{c}\text { Total Effect at } \\
\text { Ward Level }\end{array}$ \\
\hline & $(1)$ & $(2)$ & (3) & (4) & (5) & $(7)$ \\
\hline Number of Poor People & $\begin{array}{c}0.001 \\
(0.003)\end{array}$ & $\begin{array}{c}-0.011 * * * \\
(0.002)\end{array}$ & $\begin{array}{c}-0.006^{* *} \\
(0.003)\end{array}$ & $\begin{array}{c}0.760 \\
(0.597)\end{array}$ & $\begin{array}{l}-0.010 \\
(0.398)\end{array}$ & $\begin{array}{c}0.327 \\
(0.605)\end{array}$ \\
\hline Population & $\begin{array}{c}0.001 \\
(0.001) \\
\end{array}$ & $\begin{array}{c}0.007 * * * \\
(0.001) \\
\end{array}$ & $\begin{array}{c}0.004^{* * *} \\
(0.001)\end{array}$ & $\begin{array}{c}0.119 \\
(0.191) \\
\end{array}$ & $\begin{array}{c}0.888^{* * *} \\
(0.192) \\
\end{array}$ & $\begin{array}{c}0.209 \\
(0.177) \\
\end{array}$ \\
\hline Observations & 2177 & 119 & 2177 & 2177 & 119 & 2177 \\
\hline R-Squared & 0.31 & 0.513 & 0.104 & 0.308 & 0.508 & 0.02 \\
\hline District-Level Fixed Effects: & $\mathrm{Y}$ & $\mathrm{N}$ & $\mathrm{N}$ & $\mathrm{Y}$ & $\mathrm{N}$ & $\mathrm{N}$ \\
\hline
\end{tabular}

${ }^{* * *} \mathrm{p}<0.01,{ }^{* *} \mathrm{p}<0.05,{ }^{*} \mathrm{p}<0.1$. Bootstrapped standard errors in parentheses. Ward-level analysis weighted by ward population.

Between regression run at the district level and weighted by district population. Standard Errors are bootstrapped. 